\title{
Frontoparietal Correlation Dynamics Reveal Interplay between Integration and Segregation during Visual Working Memory
}

\author{
(1) Nicholas M. Dotson, ㅈodrigo F. Salazar, and Charles M. Gray \\ Cell Biology and Neuroscience, Montana State University, Bozeman, Montana 59717
}

\begin{abstract}
Working memory requires large-scale cooperation among widespread cortical and subcortical brain regions. Importantly, these processes must achieve an appropriate balance between functional integration and segregation, which are thought to be mediated by task-dependent spatiotemporal patterns of correlated activity. Here, we used cross-correlation analysis to estimate the incidence, magnitude, and relative phase angle of temporally correlated activity from simultaneous local field potential recordings in a network of prefrontal and posterior parietal cortical areas in monkeys performing an oculomotor, delayed match-to-sample task. We found longrange intraparietal and frontoparietal correlations that display a bimodal distribution of relative phase values, centered near $0^{\circ}$ and $180^{\circ}$, suggesting a possible basis for functional segregation among distributed networks. Both short- and long-range correlations display striking task-dependent transitions in strength and relative phase, indicating that cognitive events are accompanied by robust changes in the pattern of temporal coordination across the frontoparietal network.
\end{abstract}

Key words: electrophysiology; frontoparietal; monkey; oscillations; synchrony; working memory

\section{Introduction}

The realization that the primate cerebral cortex is composed of a large number of anatomically and functionally distinct cortical areas (Brodmann, 1909; DeYoe and Van Essen, 1988; GoldmanRakic, 1988; Paxinos et al., 1999; Saleem and Logothetis, 2007; Van Essen et al., 2012), widely linked by weak corticocortical connections (Zeki and Shipp, 1988; Felleman and Van Essen, 1991; Markov et al., 2014), poses a well-recognized challenge to theories of perception, action, and cognition. Somehow, large populations of neurons, distributed across widespread regions of the cortex, must rapidly and selectively cooperate in a flexible manner to enable a vast repertoire of possible functions (Mesulam, 1990; Bressler, 1995; Tononi et al., 1998; Varela et al., 2001; Bressler and Menon, 2010). A large body of evidence indicates that this functional integration occurs when distributed populations of neurons transiently form large-scale networks, defined by the spatiotemporal patterns of coordination among the participating neurons (Bressler et al., 1993; Gray, 1994; Bressler,

Received May 14, 2014; revised Aug. 1, 2014; accepted Aug. 27, 2014.

Author contributions: N.M.D., R.F.S., and C.M.G. designed research; N.M.D., R.F.S., and C.M.G. performed research; N.M.D., R.F.S., and C.M.G. analyzed data; N.M.D., R.F.S., and C.M.G. wrote the paper.

This work was supported by National Institute of Mental Health Grants MH069374 and MH081162 to C.M.G., the National Institute of Neurological Disorders and Stroke Grant NS059312 to C.M.G., the Swiss National Science Foundation to R.F.S., and the Kopriva Foundation to N.M.D. We thank Baldwin Goodell for the design and development of the microdrive systems used in this study, Steven L. Bressler for his contributions to the design of this study, and Urs Köster for technical support.

The authors declare no competing financial interests.

Correspondence should be addressed to Dr. Nicholas M. Dotson, Montana State University, 1 Lewis Hall, Bozeman, MT 59717. E-mail: nicholas.dotson@live.com.

DOI:10.1523/JNEUROSCI.1961-14.2014

Copyright $\odot 2014$ the authors $\quad 0270-6474 / 14 / 3413600-14 \$ 15.00 / 0$
1995; Singer and Gray, 1995; Roelfsema et al., 1997; Varela et al., 2001; Buzsáki, 2006; Buschman and Miller, 2007; Fell and Axmacher, 2011; Siegel et al., 2012; Crowe et al., 2013). However, this functional integration must be balanced by a competing demand for segregation to avoid false associations and globally cooperative states (Zeki and Shipp, 1988; Kelso, 1995; Bressler and Kelso, 2001; Tognoli and Kelso, 2014). Segregation could occur when competing networks are inhibited (Desimone, 1998), display statistical independence (Singer and Gray, 1995; Fries, 2005), or operate at different phases or frequencies (Bressler and Kelso, 2001; Popa et al., 2009; Tognoli and Kelso, 2014).

Working memory has the hallmark features of a cognitive process, requiring both functional integration and segregation. Endogenous and/or exogenous information no longer available in the environment, must be maintained, manipulated, and integrated with behavioral goals and decisions while resisting interference from competing representations (Miller, 2013). Recently, we reported a high incidence of task-dependent and contentspecific synchronization of activity between prefrontal (PFC) and posterior parietal (PPC) cortical areas in the $12-22 \mathrm{~Hz}$ frequency range (Salazar et al., 2012). Although these findings demonstrate that frontoparietal synchronization reflects the integration of distributed activity, the properties of the relative phase relationships and the patterns of correlation within PFC and PPC were not analyzed. Here, we use cross-correlation analysis to estimate the incidence, magnitude, and relative phase angle among pairs of local field potential (LFP) signals sampled from 63 different intra-areal and interareal combinations within and between PFC and PPC. We find widespread patterns of task-dependent correlation, largely within the previously reported frequency band, that vary in magnitude and incidence of occurrence and fall into 
two distinct phase relationships centered near $0^{\circ}$ and $180^{\circ}$. The phase relationships are dynamic and can display rapid transitions by as much as $180^{\circ}$ that are linked to task events. These findings suggest that dynamic changes in relative phase, in addition to inhibition and statistical independence, may contribute to the interplay between functional integration and segregation of distributed networks.

\section{Materials and Methods}

Subjects. Two female rhesus macaque monkeys (Monkey A and Monkey B) were each implanted with a cranial post for head restraint, scleral search coils to track eye positions (Judge et al., 1980), and two recording chambers (Gray et al., 2007) located above the prefrontal and posterior parietal cortices (see Fig. 1a) (for more details see Salazar et al., 2012). All procedures were performed in accordance with National Institutes of Health guidelines and the Institutional Animal Care and Use Committee of Montana State University.

Behavioral procedures. The monkeys were trained to perform an oculomotor, delayed match-to-sample task involving a noninstructed rule switch. The results from this study are only from trials during the identity rule (see Fig. 1b). In this task, each trial is initiated with the appearance of a central fixation spot presented on a black background. The monkey, seated in a primate chair in front of a 19 -inch monitor $(85 \mathrm{~Hz}$ refresh rate, $57 \mathrm{~cm}$ distance), is required to maintain visual fixation within a $3^{\circ}$ window throughout the trial until an appropriate oculomotor response is made. At a latency of $500 \mathrm{~ms}$, one of three possible sample objects (size, $3^{\circ}$; eccentricity, $5^{\circ}$ ) is presented for $500 \mathrm{~ms}$ at one of three possible locations lying at the vertices of an invisible triangle. This design resulted in 9 unique sample stimuli on each session. The sample stimulus is followed by a randomized delay, ranging from 800 to $1200 \mathrm{~ms}$ in one set of experiments and 1 to $3 \mathrm{~s}$ in a second set of experiments, in which no stimulus is present. At the end of the delay period, the fixation target is extinguished and a match stimulus is presented that consists of a target and a distracter object positioned at two of the three possible locations. While the match stimulus is visible, the monkey must make a saccadic eye movement to the target object and maintain gaze on the object for 300 ms. The target object is defined by the matching rule in effect, either location or identity. After the monkey had reached criterion performance ( $>80 \%$ correct responses for at least 300 consecutive trials using a sliding window of 100 trials), the rule was switched without cueing the animal. Several rule switches could occur each day, but in general only one or two switches were achieved. Correct trials were rewarded with a drop of juice. To reduce biases for both the location and identities of the objects, the object locations were rotated by $180^{\circ}$ on alternate days and each day a new set of objects was selected. All object positions and identities were presented with equal probability in a pseudorandom sequence. In Monkey B, $10 \%$ of the trials did not include stimuli and the monkey simply had to maintain fixation throughout the trial to receive a reward. The eye position signals were acquired using the scleral search coil method in Monkey A and an infrared eye-tracking system in Monkey B. Both custom software and the publicly available MonkeyLogic software (http://www.monkeylogic.net/) were used to display the stimuli and provide experimental control (Asaad and Eskandar, 2008).

Recording techniques. Broadband neuronal activity was recorded simultaneously from multiple electrodes in both the prefrontal and posterior parietal cortex (see Fig. 1a,c). The signal from each electrode was amplified (5k), filtered ( $1 \mathrm{~Hz}-10 \mathrm{kHz})$, digitized $(30 \mathrm{kHz})$, and stored for off-line analysis. In Monkey A, an acute recording method (Gray et al., 2007) was used that involved passing $4-8$ independently positioned microelectrodes (tungsten-in-glass, $0.5-1.5 \mathrm{M} \Omega$ ) through the dura on a daily basis. The horizontal separation between electrodes was at least 0.86 $\mathrm{mm}$ (range, 0.86-6.08 $\mathrm{mm}$ ), and the recording depths ranged from the point of initial detection of unit activity to a maximum of $5 \mathrm{~mm}$. Monkey $\mathrm{B}$ was implanted with two miniature mechanical microdrives containing 32 independently movable electrodes with a horizontal spacing of 1.5 $\mathrm{mm}$ and a maximum travel of $20 \mathrm{~mm}$. The maximum recording depths were $\sim 10 \mathrm{~mm}$ from the surface of the cortex. There was no attempt to identify the response properties of neurons before recording. Because of
Table 1. Sampling distribution of recording sites in both monkeys ${ }^{a}$

\begin{tabular}{|c|c|c|c|}
\hline Area & Sites recorded & $\begin{array}{l}\text { Sites with preferred } \\
\text { spike-filed phase }\end{array}$ & $\begin{array}{l}\text { Sites with preferre } \\
\text { phase near LFP tro }\end{array}$ \\
\hline \multicolumn{4}{|l|}{ Monkey A } \\
\hline $6 \mathrm{DR}$ & 0 & 0 & 0 \\
\hline $8 A D$ & 0 & 0 & 0 \\
\hline $8 \mathrm{~B}$ & 16 & 13 & 13 \\
\hline dPFC & 55 & 51 & 50 \\
\hline VPFC & 2 & 2 & 2 \\
\hline $9 \mathrm{~L}$ & 11 & 9 & 9 \\
\hline PEC & 45 & 43 & 41 \\
\hline PGM & 0 & 0 & 0 \\
\hline PE & 0 & 0 & 0 \\
\hline$P G$ & 38 & 32 & 32 \\
\hline MIP & 2 & 2 & 2 \\
\hline LIP & 5 & 4 & 4 \\
\hline Total & 174 & 156 & 153 \\
\hline \multicolumn{4}{|l|}{ Monkey B } \\
\hline $6 \mathrm{DR}$ & 14 & 14 & 14 \\
\hline $8 A D$ & 44 & 25 & 21 \\
\hline $8 B$ & 98 & 87 & 86 \\
\hline dPFC & 90 & 65 & 62 \\
\hline vPFC & 12 & 12 & 12 \\
\hline $9 \mathrm{~L}$ & 0 & 0 & 0 \\
\hline PEC & 97 & 95 & 84 \\
\hline PGM & 2 & 2 & 1 \\
\hline PE & 91 & 85 & 84 \\
\hline PG & 30 & 22 & 22 \\
\hline MIP & 66 & 65 & 63 \\
\hline LIP & 61 & 57 & 33 \\
\hline Total & 605 & 529 & 482 \\
\hline
\end{tabular}

${ }^{a}$ The first column lists the cortical area. The second column is the total number of recording sites for each area. The third column is the number of sites with nonuniform, spike-field phase distributions, indicating a preferred phase (Rayleigh test, $p<0.05$ ). The last column is the number of sites with nonuniform phase distributions and a preferred phase that is within $\pm 90^{\circ}$ (circular mean) of the LFP trough $\left(180^{\circ}\right)$. Areal abbreviations follow the nomenclature of Paxinos et al. (1999) with the exception of dPFC and vPFC:6DR, Dorsorostral area 6;8AD, anterodorsal area $8 ; 8 \mathrm{~B}$, area $8 \mathrm{~B}$; $\mathrm{dPFC}$, dorsal prefrontal cortex; $\mathrm{VPFC}$, ventral prefrontal cortex; $9 \mathrm{~L}$, lateral area $9 ; \mathrm{PEC}$, caudal area PE; PGM, medial area PG; PE, area PE; PG, area PG; MIP, medial intraparietal area; LIP, lateral intraparietal area.

the recording technique in Monkey B, $\sim 23 \%$ of signal pairs selected for analysis were recorded with electrodes at the same position during recording sessions occurring at least $24 \mathrm{~h}$ apart. In both sets of recordings, the reference and ground connections were tied together and connected to both of the recording chambers.

Signals were acquired in a trial-based format; the data acquisition hardware started and stopped recording at the beginning and end of each trial, respectively. In Monkey A, stop signals were received by the data acquisition hardware $\sim 400 \mathrm{~ms}$ after the animal made a response. In Monkey B, stop signals were sent $\sim 400 \mathrm{~ms}$ after correct responses and $\sim 1.5 \mathrm{~s}$ after incorrect responses. This additional delay served to penalize the monkey after incorrect responses. The penalty delay also enabled us to analyze the intertrial interval (ITI) following error trials for Monkey B only.

The broadband signal from each electrode was bandpass filtered (1$100 \mathrm{~Hz}$ ) and down-sampled to $1 \mathrm{kHz}$ to obtain the LFP. To extract the unit activity, the broadband signal was highpass filtered $(500 \mathrm{~Hz}$ to 7 $\mathrm{kHz}$ ). Spike waveforms were extracted by detecting local minima in the highpass signal that exceeded 4 and 5 SDs of the noise level in Monkey A and Monkey B, respectively. These waveforms were clustered using the KlustaKwik software package and further sorted using MClust (http://redishlab.neuroscience.umn.edu/MClust/MClust.html). Only channels with detectable unit activity were considered for further analysis to ensure that our signals were not in white matter.

Histology. When recording was completed, each monkey was euthanized (pentobarbital, $100 \mathrm{mg} / \mathrm{kg}$ i.v.) and perfused through the heart with PBS followed by a solution of 5\% PFA in PBS. The brain was removed and relevant portions blocked and sunk in a solution of fixative with $30 \%$ sucrose several days before being sectioned $(60 \mu \mathrm{m})$ and stained for Nissl substance to identify electrode tracks (FD Neurotech- 
nologies). Before blocking and sectioning, the brain was photographed to confirm the location of the chambers relative to major cortical sulci. Recording locations were identified from the reconstructed electrode tracks and classified according to the nomenclature of Paxinos et al. (1999).

Data selection, filtering, and spike-field anal$y$ sis. All data analysis was performed using MATLAB (MathWorks). Based on our previous analysis, we chose a frequency range for the cross-correlation analysis that closely overlapped with the content-specific patterns of frontoparietal coherence (Salazar et al., 2012). To determine the relevant upper and lower frequency limits for this analysis, we calculated the prevalence of peaks in the power spectrum of each LFP signal. The spectral power was estimated using multitaper spectral analysis (time-bandwidth product of 2, with 3 Slepian tapers, MATLAB Chronux Toolbox). The mean power during the delay period $(1.2-1.8 \mathrm{~s})$ was calculated for each channel using all correct trials during stable performance $(80 \%$ correct). The spectra were first interpolated to a resolution of $1 \mathrm{~Hz}$, smoothed (3 point moving average, 1 point step), and then investigated for peaks by finding local maxima. At each peak, the corresponding frequency was recorded. Figure $2 a$ shows five representative mean spectra with the peaks marked by red asterisks. This approach provided us with a histogram of peak frequencies across the dataset (see Fig. $2 b$ ) that revealed the incidence of spectral power that deviates from the $1 / \mathrm{f}$ distribution that is commonly observed in long duration recordings of the LFP or EEG (Buzsáki and Draguhn, 2004). The presence of a peak characterizes the dominant frequency of the oscillations; however, its absence does not exclude the presence of oscillations if the underlying magnitude of the power is high. Based on the results of this analysis, we bandpass filtered the LFP signal from 8 to $25 \mathrm{~Hz}$ (zero phase forward and reverse digital IIR fourth-order Butterworth filter) before calculating the cross-correlograms. Figure $2 c$ provides examples of two signals before and after filtering, illustrating that the dominant frequency band is not altered by the filtering.

The LFP signals were chosen for further analysis if the multiunit activity (MUA) recorded on the same channel had a preferred phase (Rayleigh test, $p<0.05$ ) within $\pm 90^{\circ}$ of the LFP trough (see Fig. 3a). This selection insured that a consistent relationship was present between the unit activity and the LFP for all signals at all recording depths. To calculate the spike-field relationships, the Hilbert transform was used to estimate the instantaneous phase of the LFP at the time of each spike (bandpass filtered at $8-25 \mathrm{~Hz}$ ). Then, a distribution of instantaneous phase values was made with these values. The circular mean of this distribution is what we refer to as the preferred phase. The Rayleigh test, which is a test for uniform circular distributions, was used to evaluate significance $(p<0.05)$. With these criteria, $\sim 79 \%$ of the PFC and $75 \%$ of the PPC recordings were selected (for the cumulative phase a

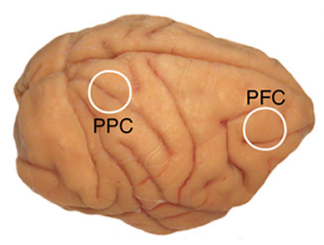

b

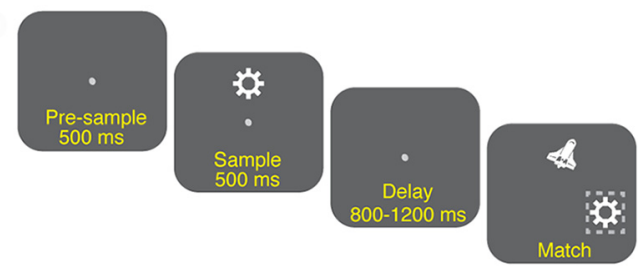

C

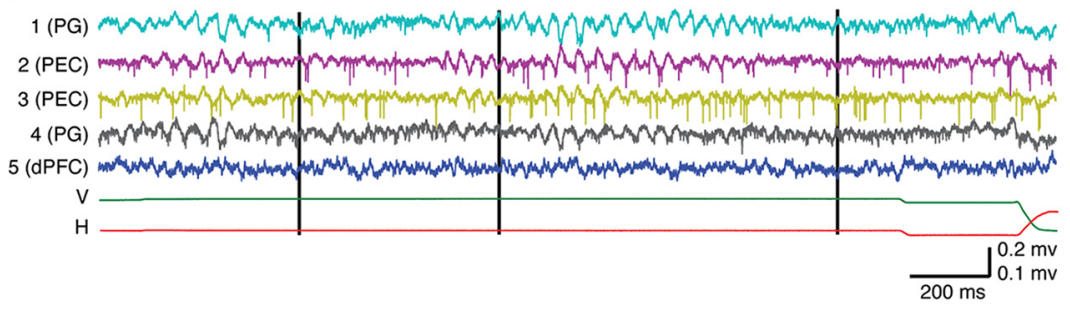

Figure 1. Illustration of recording locations, behavioral task, and an example dataset. $\boldsymbol{a}$, Recording chamber locations in Monkey $B$ superimposed on a photograph of the left hemisphere of a separate macaque brain. The chamber locations in Monkey A were similar. The prefrontal chambers were positioned over the dorsolateral PFC, and the parietal chambers were positioned over the posterior intraparietal sulcus. $\boldsymbol{b}$, Illustration of the delayed match-to-sample task. The task involved an initial fixation period $(500 \mathrm{~ms})$, followed by the presentation of a sample stimulus $(500 \mathrm{~ms})$, consisting of one of three possible objects presented at one of three possible locations, a variable delay period ( $800-1200 \mathrm{~ms}$ or $1000-3000 \mathrm{~ms}$ ) and a match stimulus, consisting of the target object and a distractor object presented at two of three possible locations. The animals successfully completed each trial by making a saccade to the target object and maintaining gaze for a minimum of $300 \mathrm{~ms}$. If the distractor was chosen, the trial immediately ended. The dashed box during the match epoch is not visible to the animal and is only included to indicate the correct choice. $c$, Example of broadband signals recorded on a single trial from Monkey A. The blackvertical lines indicate the sample onset, sample offset, and the match onset, respectively. Top and bottom voltage scales correspond to channels $1-4$ in PPC and channel 5 in PFC, respectively.
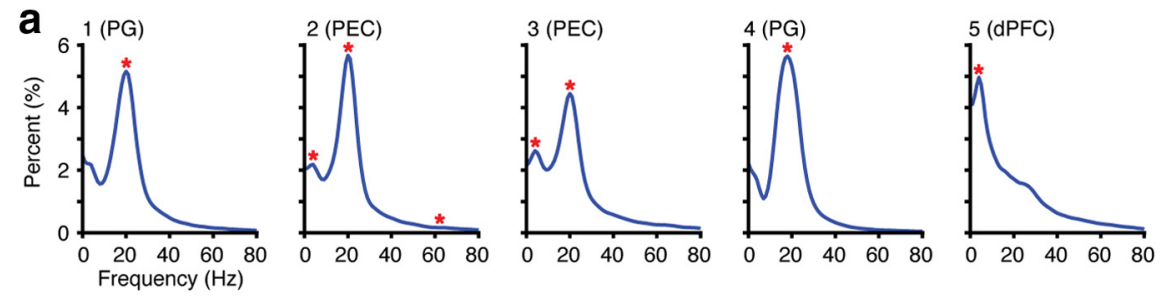

b
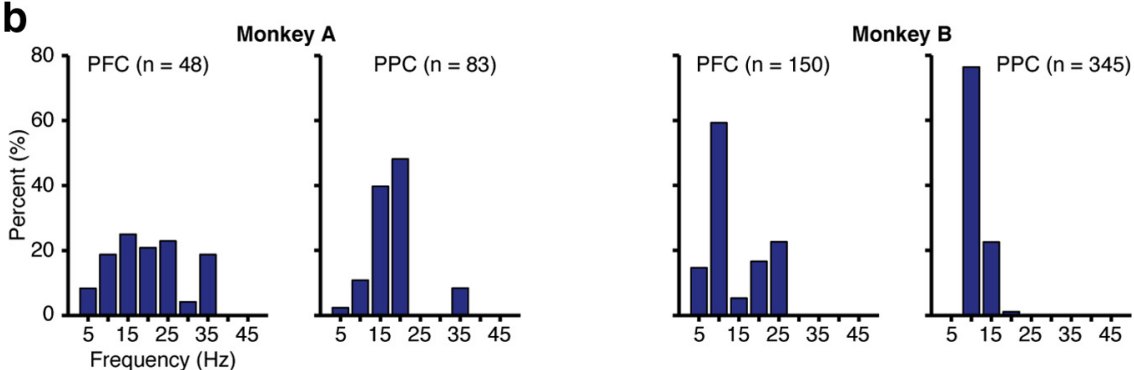

C

Delay $(1.2-1.8 \mathrm{~s})$

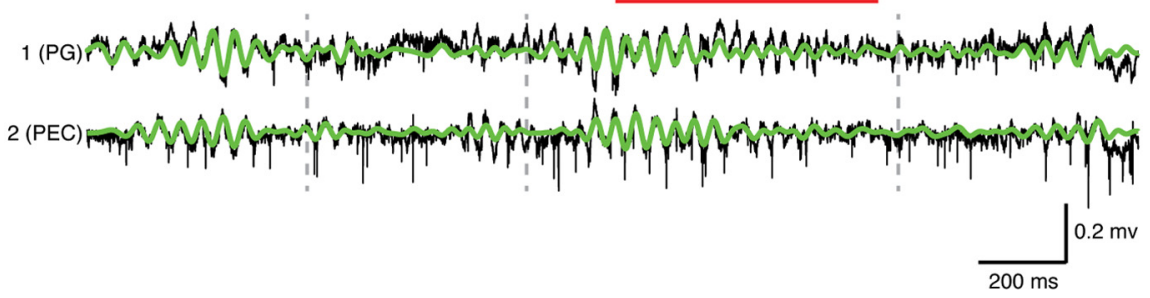

Figure 2. Summary of the spectral peak analysis. $\boldsymbol{a}$, Example of the average spectra (normalized by dividing by the integral) computed for the delay period (1.2-1.8 s) for 5 channels (same channels used for the raw data examples in Fig. 1). Red asterisks indicate where peaks were detected. $\boldsymbol{b}$, Distributions of peaks in the spectral power for Monkey A (left) and Monkey B (right) spanning the range of $5-45 \mathrm{~Hz}$ in $5 \mathrm{~Hz}$ bins. A total of 198 of $342 \mathrm{PFC}$ signals (Monkey A $=48$ of 84, Monkey $B=150$ of 258) and 428 of 437 PPC signals (Monkey $A=83$ of 90 , Monkey $B=340$ of 347 ) had peaks in their power spectrum. $c$, Example of broadband signals (black) recorded on a single trial from Monkey A with the bandpassed (8-25 $\mathrm{Hz}$ ) signals overlaid (green). These are the same broadband signals used in Figure 1, and their corresponding average spectra are shown above. Gray dashed lines indicate the sample onset, sample offset, and the match onset, respectively. 
a

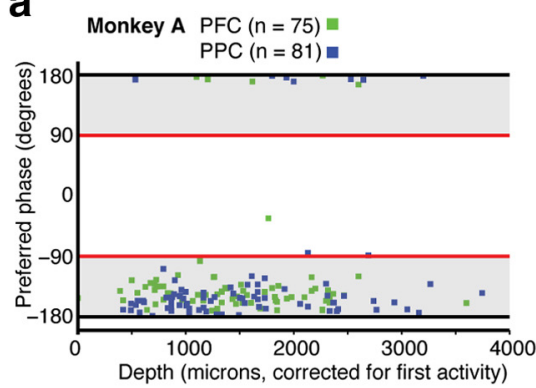

b

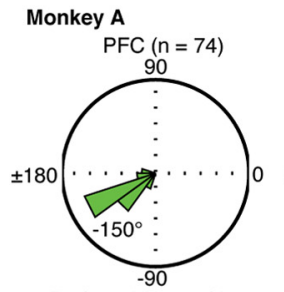

Preferred phase (degrees)

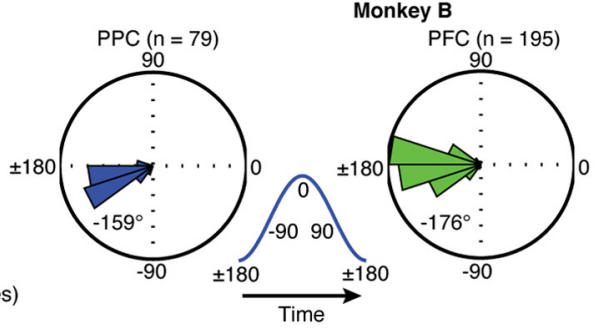

Figure 3. Summary of the spike-field phase analysis. $\boldsymbol{a}$, Distributions of the preferred phase (circular mean) of the MUA with respect to the LFP, for those sites passing the Rayleigh test $(p<0.05$ ), as a function of electrode depth. In Monkey $A$ (left), the recording depth is relative to the first detection of unit activity near the cortical surface. In Monkey $B$ (right), the recording depth is relative to the starting position of the electrodes in the microdrive. A circular mean near $180^{\circ}$ indicates that the MUA is concentrated near the trough, or negative phase, of the LFP (shaded region). $\boldsymbol{b}$, Circular histograms of the preferred phase (circular mean) for all signals that passed the Rayleigh test with a circular mean $>90^{\circ}$ in absolute value. Inset (middle), The timing of spikes relative to the LFP oscillation, with the negative trough at $\pm 180^{\circ}$. The grand circular mean is given in the bottom left of each histogram.
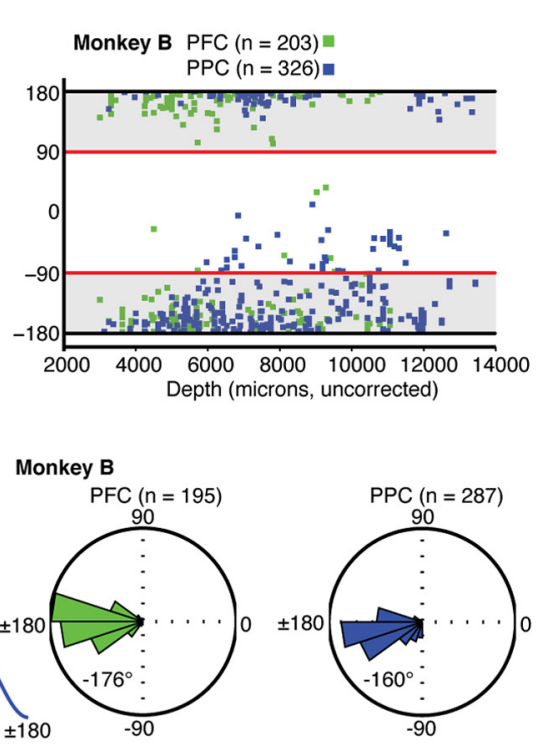

used to compare the magnitude of correlation between the presample and delay periods, and the delay and ITI periods.

It could be argued that the use of a timefrequency domain analysis, such as coherence analysis, would be more useful because it avoids bandpass filtering the data. We chose to use cross-correlation analysis for several reasons. First, using the band-passed signal, we were able to directly assess the relative phase between the dominant components in the signals, rather than a combination of phase and amplitude. Second, it provided a single value for the magnitude and phase for the frequency at which the signals were maximally correlated, greatly simplifying the analysis.

ITI spectral power analysis. To determine the time course of the average power during the ITI, we first calculated the timefrequency power spectra (200 ms sliding window stepped at $50 \mathrm{~ms}$ ) using multitaper spectral analysis (time-bandwidth product of 2, and 3 Slepian tapers, MATLAB Chronux Toolbox). Second, the maximum power at $\sim 19 \mathrm{~Hz}$ was estimated relative to the match onset for each signal. The search window was delayed $200 \mathrm{~ms}$ after the behavioral choice to avoid activity evoked by the match stimulus. This provided us with a single value for each signal at the time after match onset where the power at $\sim 19 \mathrm{~Hz}$ was highest. distributions, see Fig. $3 b$; for areal information, see Table 1).

Cross-correlation analyses. All cross-correlations were performed using the MATLAB built-in function "xcorr.m" (correlation coefficients range from -1 to 1$)$. The average cross-correlogram ( $\pm 50 \mathrm{~ms}$ time lag, data down-sampled to $1 \mathrm{kHz})$ of the LFP $(8-25 \mathrm{~Hz})$ for each pair of signals was calculated across all correct identity trials (stable performance, $>80 \%$ correct) (Salazar et al. (2012)) and all stimuli during the presample (0.1-0.5 s) and the delay period (1.2-1.8 s and 1.4-1.8 s). Because of our data acquisition technique at the time of recording, the average cross-correlograms during the ITI (0.5-0.9 s after match onset) were calculated from the incorrect trials for Monkey B only (see above for details). In order to compare the delay and ITI periods for Monkey B, the average cross-correlograms were also calculated from the incorrect trials in Monkey B during the delay period (1.4-1.8 s). The frequency of each correlogram was determined by fitting an 8 parameter generalized Gabor function (König, 1994) with the minimum squared error used as the criterion for the best fit. This approach has been widely used to quantitatively characterize the properties of auto- and cross-correlograms (e.g., Freeman, 1975; Gray and Skinner, 1988). The central peak (positive or negative) obtained from the fitted Gabor function was determined by finding the local maximum or minimum that was closest to zero time lag. The relative phase angle between the two LFPs was calculated using the time lag, polarity of the central peak, and the frequency estimated from the Gabor function. Correlograms that were near $180^{\circ}$ out of phase had a distinct trough near zero time lag (for examples, see Fig. $4 f, h$ ). We used two criteria to identify signal pairs that were significantly correlated: (1) the absolute value of the correlation coefficient at the central peak (positive or negative) was $>0.1\left(\sim p<10^{-20}\right.$, randomization test), and (2) the correlation coefficient between the original correlogram and the Gabor function was $\geq 0.99$. To visualize the temporal aspects of these cross-correlations, time-dependent average cross-correlograms were calculated using a $200 \mathrm{~ms}$ window, a $50 \mathrm{~ms}$ time step, and a $\pm 50 \mathrm{~ms}$ time lag (for examples, see Figs. $4 a-d$ and $11 b-d$ ). To compare the results between task periods, we used a sign test (paired, two-sided, $p<0.05$ using the Benjamini-Hochberg procedure to control the false discovery rate), which tests the hypothesis that the difference median is zero. This was

\section{Results}

We recorded broadband neuronal activity from multiple electrodes in multiple areas of the PFC and the PPC in two monkeys (Monkey A and Monkey B) while the animals performed an oculomotor, delayed match-to-sample task (Fig. 1). The animals performed either an identity-matching rule or a locationmatching rule in blocks, with a noncued rule switch (see Materials and Methods). Trials were pooled across stimuli, and only trials recorded during stable performance $(>80 \%$ correct) on the identity-matching rule were used for this analysis.

A total of $342 \mathrm{PFC}$ and $437 \mathrm{PPC}$ recordings were acquired (Table 1). Before performing any analyses, we bandpass filtered the LFP signals between 8 and $25 \mathrm{~Hz}$ and chose signals for further analysis when the MUA recorded on the same electrode had a preferred phase within $\pm 90^{\circ}$ of the LFP trough (Rayleigh test, $p<$ $0.05)$. This ensured that the LFP signals in this frequency range had a consistent relationship with the unit activity on the same electrode. With this criterion, $79 \%$ of the PFC and $75 \%$ of the PPC recordings were selected for correlation analysis (see Materials and Methods) (Figs. 2 and 3; Table 1).

\section{Frontoparietal correlations during working memory}

To determine the patterns of functional connectivity across the frontoparietal network, we used cross-correlation analysis to estimate the incidence, magnitude, and relative phase angle between all combinations of simultaneously recorded LFPs during the delay period of the task. We found significant correlations in $60 \%$ and $48 \%$ of the signal pairs in Monkey A and Monkey B, respectively, resulting in 1644 significantly correlated signal pairs from 63 different intra-areal and interareal combinations (Table 2; for selection criteria, see Materials and Methods). Figure 4 shows four examples of the signal correlations we observed in the data from Figure $1 c$. During the task, the correlation magnitude 
Table 2. Counts for all areal combinations before any selection criteria, and for four different subsets with selection criteria ${ }^{a}$

\begin{tabular}{|c|c|c|c|c|c|c|}
\hline Area 1 & Area 2 & $\begin{array}{l}\text { 1: Signal } \\
\text { pairs }\end{array}$ & $\begin{array}{l}\text { 2: Significant } \\
\text { signal pairs }\end{array}$ & $\begin{array}{l}\text { 3: Significant } \\
\text { signal pairs } \\
\text { near } 180^{\circ}\end{array}$ & $\begin{array}{l}\text { 4: Significant } \\
\text { signal pairs } \\
\text { (presample } \\
\text { vs delay) }\end{array}$ & $\begin{array}{l}\text { 5: Significant } \\
\text { signal pairs } \\
\text { (ITI vs delay) }\end{array}$ \\
\hline \multicolumn{7}{|l|}{ Monkey A } \\
\hline $8 B$ & $9 \mathrm{~L}$ & 8 & 7 & 0 & 7 & - \\
\hline $\mathrm{dPFC}$ & $9 \mathrm{~L}$ & 3 & 2 & 0 & 2 & - \\
\hline PEC & $9 \mathrm{~L}$ & 15 & 8 & 1 & 7 & - \\
\hline PG & $9 \mathrm{~L}$ & 5 & 1 & 1 & 0 & - \\
\hline $9 \mathrm{~L}$ & $9 \mathrm{~L}$ & 4 & 2 & 0 & 2 & - \\
\hline $8 B$ & $8 B$ & 5 & 5 & 0 & 5 & - \\
\hline $8 B$ & $\mathrm{dPFC}$ & 13 & 12 & 0 & 11 & - \\
\hline $8 B$ & PEC & 25 & 20 & 2 & 14 & - \\
\hline $8 B$ & PG & 21 & 7 & 7 & 6 & - \\
\hline $8 B$ & MIP & 1 & 1 & 0 & 1 & - \\
\hline $8 B$ & LIP & 1 & 0 & 0 & 0 & - \\
\hline $\mathrm{dPFC}$ & dPFC & 43 & 33 & 0 & 32 & - \\
\hline dPFC & vPFC & 7 & 6 & 0 & 5 & - \\
\hline dPFC & PEC & 74 & 26 & 2 & 18 & - \\
\hline dPFC & $P G$ & 53 & 16 & 15 & 6 & - \\
\hline $\mathrm{dPFC}$ & MIP & 6 & 5 & 0 & 3 & - \\
\hline $\mathrm{dPFC}$ & LIP & 6 & 5 & 5 & 3 & - \\
\hline vPFC & PEC & 5 & 2 & 0 & 2 & - \\
\hline vPFC & $P G$ & 2 & 2 & 1 & 1 & - \\
\hline PEC & PEC & 29 & 28 & 1 & 27 & - \\
\hline PEC & $P G$ & 34 & 23 & 17 & 22 & - \\
\hline PEC & MIP & 4 & 4 & 0 & 4 & - \\
\hline PEC & LIP & 1 & 0 & 0 & 0 & - \\
\hline PG & PG & 21 & 17 & 0 & 18 & - \\
\hline$P G$ & MIP & 2 & 1 & 1 & 2 & - \\
\hline \multirow[t]{2}{*}{ PG } & LIP & 2 & 2 & 0 & 2 & - \\
\hline & Total & 390 & 235 & 53 & 200 & - \\
\hline \multicolumn{7}{|c|}{ Monkey B } \\
\hline $6 \mathrm{DR}$ & $6 \mathrm{DR}$ & 2 & 0 & 0 & 0 & 0 \\
\hline $6 \mathrm{DR}$ & $8 A D$ & 12 & 6 & 1 & 2 & 6 \\
\hline $6 \mathrm{DR}$ & $8 \mathrm{~B}$ & 31 & 12 & 3 & 6 & 8 \\
\hline $6 \mathrm{DR}$ & $\mathrm{dPFC}$ & 17 & 8 & 2 & 7 & 6 \\
\hline 6DR & PEC & 50 & 2 & 1 & 1 & 1 \\
\hline $6 \mathrm{DR}$ & PE & 49 & 2 & 1 & 0 & 3 \\
\hline $6 \mathrm{DR}$ & $P G$ & 10 & 0 & 0 & 0 & 0 \\
\hline $6 \mathrm{DR}$ & LIP & 17 & 3 & 3 & 3 & 0 \\
\hline $8 A D$ & $8 \mathrm{AD}$ & 6 & 6 & 0 & 6 & 6 \\
\hline $8 A D$ & $8 B$ & 58 & 38 & 4 & 32 & 34 \\
\hline $8 A D$ & dPFC & 36 & 31 & 0 & 31 & 26 \\
\hline $8 A D$ & vPFC & 6 & 4 & 0 & 5 & 4 \\
\hline $8 A D$ & PEC & 61 & 17 & 1 & 13 & 3 \\
\hline $8 A D$ & PE & 69 & 40 & 0 & 32 & 20 \\
\hline $8 \mathrm{AD}$ & $P G$ & 17 & 9 & 0 & 3 & 7 \\
\hline $8 A D$ & PGM & 1 & 1 & 0 & 1 & 0 \\
\hline $8 A D$ & MIP & 9 & 1 & 0 & 0 & 0 \\
\hline $8 \mathrm{AD}$ & LIP & 16 & 0 & 0 & 0 & 3 \\
\hline $8 B$ & $8 B$ & 75 & 19 & 5 & 16 & 18 \\
\hline $8 B$ & $\mathrm{dPFC}$ & 135 & 62 & 9 & 51 & 41 \\
\hline $8 B$ & vPFC & 31 & 6 & 0 & 7 & 6 \\
\hline $8 B$ & PEC & 196 & 66 & 1 & 54 & 43 \\
\hline $8 B$ & PE & 191 & 89 & 0 & 84 & 70 \\
\hline $8 B$ & $P G$ & 51 & 30 & 16 & 17 & 17 \\
\hline $8 B$ & PGM & 2 & 0 & 0 & 0 & 0 \\
\hline $8 B$ & MIP & 118 & 12 & 10 & 1 & 3 \\
\hline $8 B$ & LIP & 58 & 34 & 34 & 24 & 28 \\
\hline dPFC & $\mathrm{dPFC}$ & 35 & 26 & 0 & 26 & 25 \\
\hline $\mathrm{dPFC}$ & vPFC & 19 & 12 & 0 & 8 & 8 \\
\hline dPFC & PEC & 128 & 35 & 0 & 19 & 13 \\
\hline $\mathrm{dPFC}$ & PE & 143 & 74 & 0 & 62 & 44 \\
\hline $\mathrm{dPFC}$ & $P G$ & 42 & 25 & 7 & 13 & $\begin{array}{c}13 \\
\text { able continues.) }\end{array}$ \\
\hline
\end{tabular}

Table 2. Continued

\begin{tabular}{|c|c|c|c|c|c|c|}
\hline Area 1 & Area 2 & $\begin{array}{l}\text { 1: Signal } \\
\text { pairs }\end{array}$ & $\begin{array}{l}\text { 2: Significant } \\
\text { signal pairs }\end{array}$ & $\begin{array}{l}\text { 3: Significant } \\
\text { signal pairs } \\
\text { near } 180^{\circ}\end{array}$ & $\begin{array}{l}\text { 4: Significant } \\
\text { signal pairs } \\
\text { (presample } \\
\text { vs delay) }\end{array}$ & $\begin{array}{l}\text { 5: Significant } \\
\text { signal pairs } \\
\text { (ITI vs delay) }\end{array}$ \\
\hline dPFC & PGM & 2 & 1 & 0 & 2 & 2 \\
\hline dPFC & MIP & 62 & 16 & 0 & 10 & 10 \\
\hline \multicolumn{7}{|c|}{ Monkey B } \\
\hline dPFC & LIP & 47 & 13 & 2 & 8 & 7 \\
\hline VPFC & vPFC & 7 & 7 & 0 & 7 & 2 \\
\hline VPFC & PEC & 5 & 0 & 0 & 0 & 0 \\
\hline vPFC & PE & 16 & 12 & 0 & 9 & 0 \\
\hline vPFC & MIP & 52 & 4 & 0 & 2 & 3 \\
\hline VPFC & LIP & 16 & 0 & 0 & 0 & 2 \\
\hline vPFC & PGM & 3 & 0 & 0 & 0 & 0 \\
\hline PEC & PEC & 92 & 78 & 0 & 63 & 61 \\
\hline PEC & PE & 260 & 188 & 0 & 158 & 153 \\
\hline PEC & PG & 58 & 23 & 21 & 16 & 9 \\
\hline PEC & MIP & 52 & 47 & 0 & 46 & 44 \\
\hline PEC & LIP & 77 & 31 & 22 & 21 & 7 \\
\hline PE & PE & 120 & 114 & 0 & 100 & 106 \\
\hline PE & $P G$ & 56 & 23 & 22 & 20 & 14 \\
\hline PE & MIP & 51 & 32 & 0 & 28 & 32 \\
\hline PE & LIP & 91 & 37 & 37 & 38 & 17 \\
\hline PG & $P G$ & 4 & 4 & 0 & 4 & 3 \\
\hline$P G$ & LIP & 10 & 7 & 0 & 7 & 9 \\
\hline MIP & MIP & 96 & 80 & 0 & 69 & 75 \\
\hline MIP & LIP & 60 & 0 & 0 & 2 & 0 \\
\hline LIP & LIP & 15 & 14 & 0 & 13 & 13 \\
\hline PGM & PE & 2 & 2 & 0 & 2 & 2 \\
\hline PGM & MIP & 6 & 4 & 0 & 3 & 3 \\
\hline \multirow[t]{2}{*}{ PGM } & LIP & 2 & 2 & 2 & 2 & 2 \\
\hline & Total & 2953 & 1409 & 204 & 1154 & 1032 \\
\hline
\end{tabular}

${ }^{a}$ Column 1, The total number of signal pairs. Column 2, The total number of signal pairs during the delay (1.2-1.8s) that pass the cross-correlogram selection criteria. Column 3, The total number of signal pairs during the delay $(1.2-1.8 \mathrm{~s})$ that pass the cross-correlogram selection criteria and have a relative phase angle near $180^{\circ}\left(|\theta|>90^{\circ}\right)$. Column 4 , The total number of signal pairs that pass the cross-correlogram selection criteria during the delay $(1.4-1.8 \mathrm{~s})$ and the presample $(0.1-0.5 \mathrm{~s})$. Column 5 , The total number of signal pairs that pass the crosscorrelogram selection criteria during the delay (1.4-1.8s) and the ITI (0.5- 0.9 s after match onset), during incorrect trials (Monkey B only). Areal abbreviations are the same as in Table 1.

peaks before the sample, transiently declines, and then increases again during the delay (Fig. $4 a-d$ ). These magnitude changes are accompanied by subtle shifts in the relative phase angle, especially during the response to the sample when the correlation magnitude is at its minimum. Notably, the correlation magnitudes and phase relationships are related to the cortical locations of the recording sites. In these examples, the PEC-PEC signal pair, recorded medial to the intraparietal sulcus (IPS), exhibits a strong, in-phase correlation (Fig. 4a,e), whereas the PG-PEC signal pair, recorded from opposite sides of the IPS, displays a weaker, but nearly anti-phase, correlation (Fig. $4 b$,f). Similar phase relationships are present in the long-distance frontoparietal signal pairs. The dPFC-PEC (Fig. $4 c, g$ ) and dPFC-PG (Fig. $4 d, h$ ) signal pairs display weaker correlations while maintaining a striking difference in relative phase.

Analysis of the incidence and magnitude of correlation with respect to spatial separation revealed distinct patterns of functional connectivity. We evaluated these effects by grouping signal pairs into six categories: (1) within PFC, (2) PPC signals medial to the IPS, (3) PPC signals lateral to the IPS, (4) PPC signals on opposite sides of the IPS, (5) PFC and medial PPC pairs, and (6) PFC and lateral PPC pairs. As shown in Table 3 , the incidence and magnitude of correlation were highest among signal pairs recorded on the same side of the IPS, somewhat lower within PFC, and markedly lower for signal pairs separated by larger distances 
a

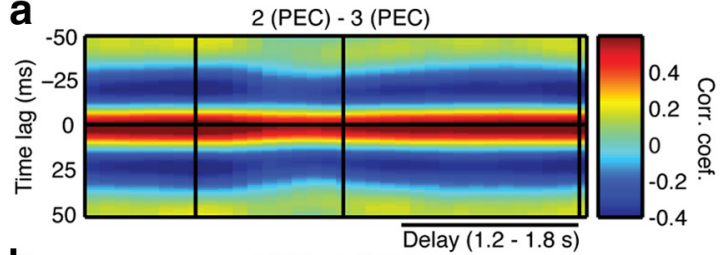

b

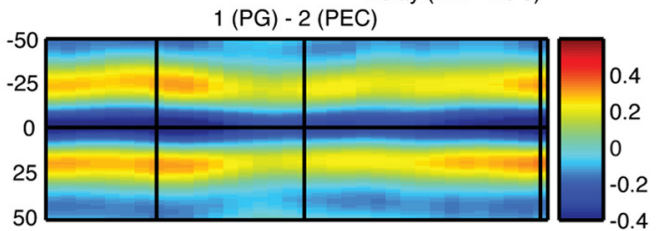

C

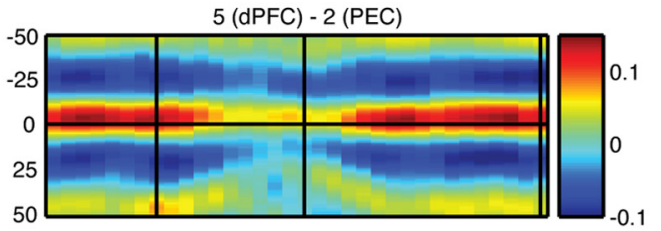

d

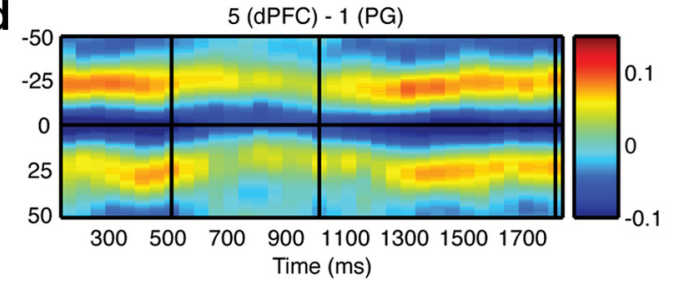

e

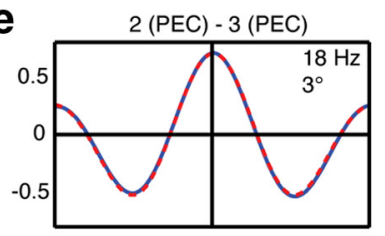

f

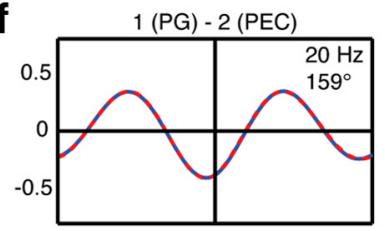

g

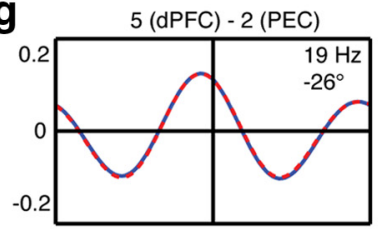

$\mathbf{h}$

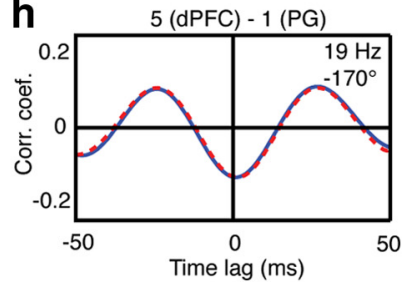

Figure 4. Example of cross-correlation results. $\boldsymbol{a}$ - $\boldsymbol{d}$, Average cross-correlograms as a function of time ( $200 \mathrm{~ms}$ window, $50 \mathrm{~ms}$ step) for four of the signal pairs shown in Figure $1 c$. Vertical black lines indicate the sample onset, sample offset, and earliest match onset, respectively. $\boldsymbol{e}-\boldsymbol{h}$, Average cross-correlograms (blue curves) calculated from correct trials during the delay period (1.2-1.8 s) and generalized Gabor functions that were fit to the data (dashed red curves). The frequency and phase angle obtained from the Gabor function are indicated in the upper right of each plot.

Table 3. The incidence and magnitude of significant correlation with respect to cortical regions $^{a}$

\begin{tabular}{lll}
\hline Combination & Incidence (\%) & Magnitude median (25th/75th) \\
\hline PFC-PFC & 55 & $0.39(0.27 / 0.51)$ \\
mPPC-mPPC & 81 & $0.50(0.38 / 0.61)$ \\
IPPC-IPPC & 85 & $0.71(0.54 / 0.79)$ \\
mPPC-IPPC & 37 & $0.17(0.13 / 0.22)$ \\
PFC-mPPC & 34 & $0.15(0.12 / 0.20)$ \\
PFC-IPPC & 40 & $0.18(0.14 / 0.22)$
\end{tabular}

$\overline{\text { ancidence is reported as a single percentage across all measurements in each category. Magnitude is reported as the }}$ median (25th/75th percentiles). The results are grouped into six categories: PFC, mPPC-mPPC, IPPC-IPPC, mPPCIPPC, PFC-mPPC, and PFC-IPPC. PFC, Prefrontal; mPPC, medial posterior parietal; IPPC, lateral posterior parietal.

(i.e., mediolateral parietal, frontoparietal). To assess the effect of interelectrode separation on correlation magnitude within PFC and PPC, we plotted the correlation magnitude versus distance for all pairs within PFC, and together for all pairs on the same side of the IPS. This revealed a fall off of correlation magnitude as a function of distance for electrode separations $<6 \mathrm{~mm}$ (Fig. 5). Thus, the magnitude of correlation decreases with distance within and between adjacent areas of the PFC and PPC (Murthy and Fetz, 1996; Destexhe et al., 1999), whereas both the incidence and magnitude of correlation plateau to lower levels over distances that span widely separated areas of cortex (Roelfsema et al., 1997).

Consistent with the results in Figure 4, we found a clear bimodal distribution of relative phase values among significantly correlated pairs in both monkeys (Fig. 6). With all data combined, the distributions of relative phases were split into approximately in-phase $\left(\right.$ near $0^{\circ}$ ) and anti-phase (near $180^{\circ}$ ) modes (Fig.

$6 a, e)$. To identify the source of these distinct modes, we separated the data into PFC, PPC, and frontoparietal categories. Within PFC, the vast majority of phase values are centered near $0^{\circ}$ in both monkeys (Fig. 6b, $f$ ). Within PPC, the relative phase distributions are distinctly bimodal in both monkeys, with the dominant mode centered near $0^{\circ}$ and the secondary mode centered near $180^{\circ}$ (Fig. $6 c, g$ ). These bimodal phase distributions also exist in the frontoparietal correlations in both animals (Fig. $6 d, h$ ): The dominant mode, centered near $-16^{\circ}$ in both monkeys, displays a prefrontal phase lead, as previously reported (Salazar et al., 2012), whereas the secondary mode is more broadly distributed and centered at $-180^{\circ}$ and $-148^{\circ}$ in Monkey A and Monkey B, respectively (Table 4).

To gain further insight into these processes, we subdivided the correlation analysis with respect to each intra-areal and interareal combination of signals. The magnitude, relative phase, and frequency values of the correlations are shown in Figure 7 . Because the sign of the relative phase angle can be ambiguous, we report the absolute value of the relative phase. The results reveal that the patterns of correlation are anatomically specific. Within PFC, the correlations vary widely in magnitude with respect to areal combination (and thus distance) and are dominated by in-phase relationships, with a small percentage of values scattered $\sim 100^{\circ}$ in Monkey B (Fig. $7 a$ ). Within PPC, signal pairs recorded on either the medial (Fig. 7b) or the lateral (Fig. 7c) side of the IPS have a broad distribution of correlation magnitudes and are highly clustered in-phase, with only one value exceeding $90^{\circ}$. In contrast, the long-distance correlations between signals recorded on the medial and lateral sides of the IPS, and between these areas and the PFC, are smaller in magnitude and exhibit a clear bimodal distribution of phase values (Fig. $7 d-f$ ). Signal pairs recorded on opposite sides of the IPS are dominated, with some exceptions, by near anti-phase relationships (Fig. $7 d$ ). Signal pairs recorded in PFC and the medial side of the IPS (Fig. 7e) are dominated by in-phase relationships, with the exception of signals sampled from areas $8 \mathrm{~B}$ and MIP in Monkey B that are almost entirely out-of-phase. In contrast, signal pairs recorded in PFC and the lateral side of the IPS (Fig. $7 f$ ) exhibit both unimodal and bimodal phase distributions that are anatomically specific. In Monkey A, all signal pairs, except one, have phase values $>90^{\circ}$. In Monkey B, correlations between prefrontal and lateral parietal signals are either exclusively out-of-phase (8B-LIP), exclusively in-phase (8AD-PG), or bimodally distributed (8B-PG, dPFC-PG, dPFC-LIP). Figure 7 (bottom row of plots) shows the corresponding frequencies of correlation derived from the fitted functions. The frequencies vary within the band of interest, display some subtle difference with respect to areal combination, and differ between the two animals. Moreover, there is no apparent difference in correlation magnitudes between the two animals (also see Fig. 5), even though the dominant frequencies are different. Clear examples of this can be seen by examining the distributions for the 
dPFC-PEC and PEC-PEC pairs. These subtle differences in frequency may provide another means for balancing integration and segregation.

In addition to the abundance of correlated interactions, we also found a number of interareal pairings with significant correlation occurring $\leq 10 \%$ of the time (Fig. 8; Table 2). Although this effect might be related to small sample sizes (e.g., 6DR-PG) and thus reflect an experimental bias, other interareal combinations have $\geq 50$ signal pairs and show a very low probability of correlation. For example, none of the cross-correlograms computed from the 60 MIP-LIP signal pairs in Monkey B reached significance. This indicates that these and other areas are functioning largely independently under the conditions of this experiment.

To further illustrate the specificity of these interactions, Figure 9 shows the correlation patterns obtained from a single recording session in Monkey B. Within PFC, the signal correlations have values $<0.5$ and, with one exception, display relative phase values $<45^{\circ}$ (Fig. 9c). The intraparietal signals exhibit stronger correlations having relative phase values $<45^{\circ}$ when the signals are recorded on the same sides of the IPS, and weaker correlations with relative phases $>135^{\circ}$ for recordings on opposite sides of the IPS (Fig. 9d). The frontoparietal correlations are weaker and display relative phase values that are clustered into two groups (Fig. $9 e$ ): those $<45^{\circ}$ and those $>135^{\circ}$. This segregation of phases, as in Figure 4, displays some anatomical boundaries. Signals in area $8 \mathrm{~B}$ exhibit near anti-phase relationships with signals recorded in areas LIP and MIP, even though the signals in LIP and MIP are statistically independent (Fig. 8). The remaining prefrontal signals in this example in areas $8 \mathrm{AD}, \mathrm{dPFC}$, and $\mathrm{vPFC}$ have in-phase relationships with parietal signals recorded in areas that are medial to the IPS but are statistically independent from signals recorded lateral to the IPS, even though significant antiphase correlations occur between signals that span the IPS. These patterns of correlation suggest that in-phase and anti-phase relationships are established at different times among different sites in the network.

\section{Task-dependent correlation patterns}

Next, we examined the task dependence of frontoparietal correlations by comparing the presample period (0.1-0.5 s) with a window of the same size in the delay period that is locked to the first possible match $(1.4-1.8 \mathrm{~s})$. Signal pairs were selected using the same criteria, but for both task periods, resulting in a new set of signal pairs (Table 2). We tested whether the correlation increased or decreased between the presample and delay periods for each areal combination (sign test, paired, two-sided) and plotted the difference distributions (minimum of 5 signal pairs) pooled across both animals (Fig. 10). Several trends emerged from this analysis. Within PFC, a small, but significant, increase in correlation occurred during the delay for areal combinations $8 \mathrm{~B}-8 \mathrm{~B}$, 8B-8AD, and 8B-dPFC. Within PPC, correlations displayed a distinct pattern of changes: areas medial to the IPS displayed a robust increase in correlation during the delay (Fig. 10b), those lateral to the IPS showed no change (Fig. 10c), and areas separated by the IPS tended to decrease during the delay, but only
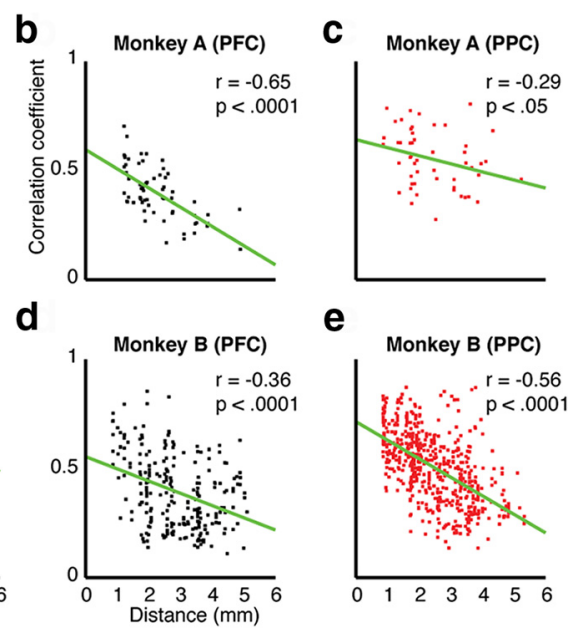

Figure 5. Summary of the relationship between distance and correlation magnitude during the delay period (1.2-1.8s). $a$, All signal pairs recorded in PFC (black squares) and from the same side of the IPS in PPC (red squares) for both animals. $\boldsymbol{b}, \boldsymbol{c}$, Signal pairs corded in PFC and PPC from Monkey A. $\boldsymbol{d}$, e, Signal pairs recorded in PFC and PPC from Monkey B. Green lines indicate the least-squares fit: correlation values $(r)$ are provided in the upper right of each plot, along with $p$ values for testing the hypothesis of

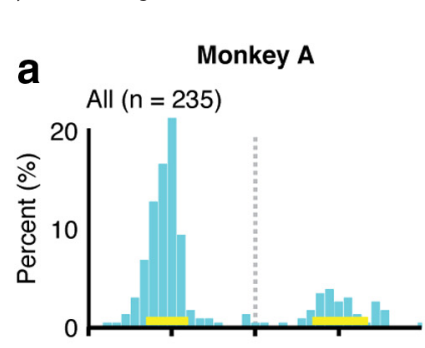

b
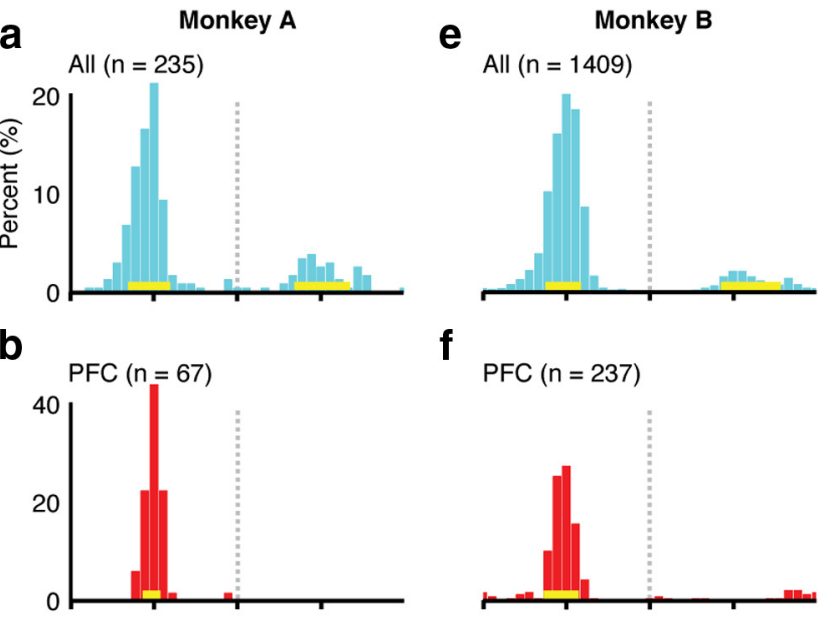

$\mathbf{f}$

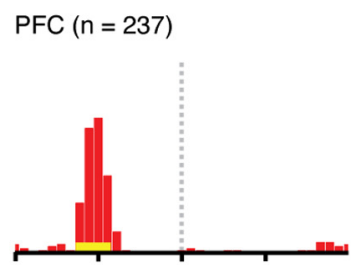

C

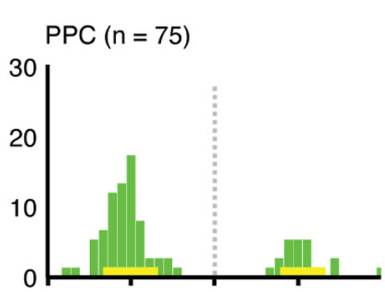

$9 \operatorname{PPC}(n=686)$

d
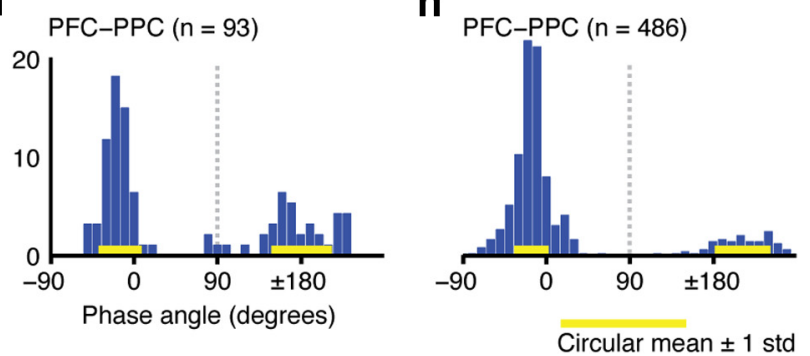

Figure 6. Distributions of the relative phase angles during the delay period $(1.2-1.8 \mathrm{~s})$ for different combinations of signal pairs recorded from Monkey A (left column) and Monkey $B$ (right). $\boldsymbol{a}-\boldsymbol{d}$, All, PFC, PPC, and PFC-PPC signal pairs for Monkey A. $\boldsymbol{e}-\boldsymbol{h}$, All, PFC, PPC, and PFC-PPC signal pairs for Monkey $B$. The yellow bars represent the circular mean \pm 1 circular SD for each identifiable mode. 
Table 4. Data accompanying Figure $6^{a}$

\begin{tabular}{|c|c|c|c|c|c|c|c|c|}
\hline \multirow[b]{2}{*}{ Combination } & \multicolumn{4}{|l|}{ Monkey A } & \multicolumn{4}{|l|}{ Monkey B } \\
\hline & $\begin{array}{l}\text { Count } \\
\text { (in-phase) }\end{array}$ & $\begin{array}{l}\text { In-phase } \\
\text { (mean } \pm \text { SD) }\end{array}$ & $\begin{array}{l}\text { Count } \\
\text { (anti-phase) }\end{array}$ & $\begin{array}{l}\text { Anti-phase } \\
\text { (mean } \pm \text { SD) }\end{array}$ & $\begin{array}{l}\text { Count } \\
\text { (in-phase) }\end{array}$ & $\begin{array}{l}\text { In-phase } \\
\text { (mean } \pm \text { SD) }\end{array}$ & $\begin{array}{l}\text { Count } \\
\text { (anti-phase) }\end{array}$ & $\begin{array}{l}\text { Anti-phase } \\
\text { (mean } \pm \text { SD) }\end{array}$ \\
\hline All & 182 & $-7.3 \pm 20.7$ & 53 & $181.7 \pm 30.0$ & 1205 & $-5 \pm 19.1$ & 204 & $199.5 \pm 32.1$ \\
\hline PFC & 67 & $-0.2 \pm 12.2$ & 0 & NA & 213 & $-5.5 \pm 18.9$ & 24 & NA \\
\hline PPC & 56 & $-8.0 \pm 22.5$ & 19 & $185.2 \pm 24.4$ & 582 & $6.3 \pm 13.5$ & 104 & $185.3 \pm 18.1$ \\
\hline PFC-PPC & 59 & $-15.2 \pm 23.6$ & 34 & $-179.5 \pm 32.6$ & 410 & $-15.9 \pm 18.7$ & 76 & $-148.0 \pm 30.0$ \\
\hline
\end{tabular}

${ }^{a}$ With all data combined, and with the data subdivided into PFC, PPC, and PFC-PPC categories, the distributions of relative phase angles were split into approximately in-phase and anti-phase modes, with a dividing line centered at $\pm 90^{\circ}$. Here we report the counts and the circular mean \pm SD for the in-phase and out-of-phase signal pairs. No out-of-phase data are reported for the PFC combination because of the lack of any distinct mode. NA, Not applicable.

a

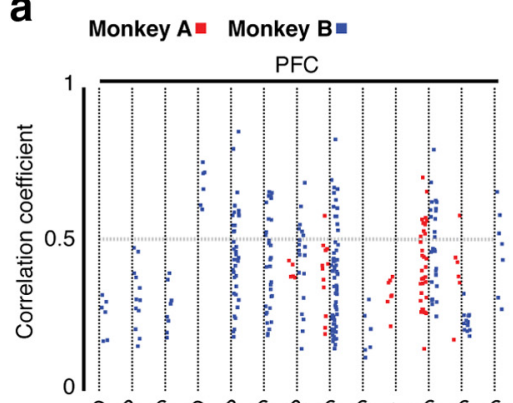

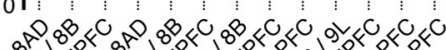
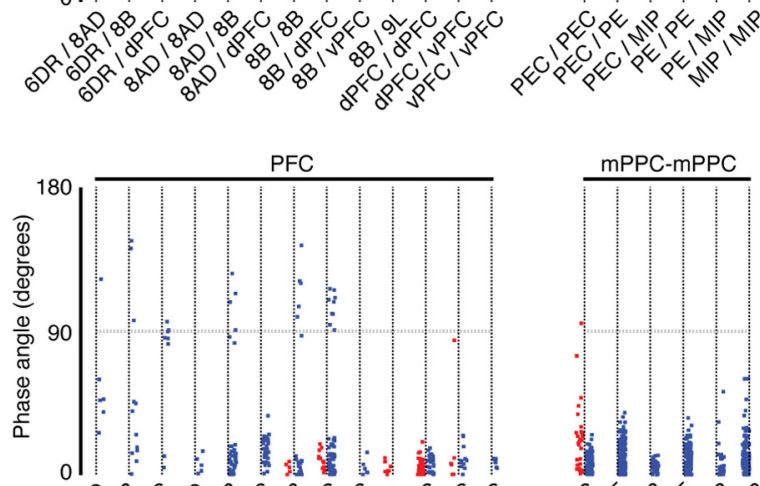

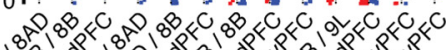
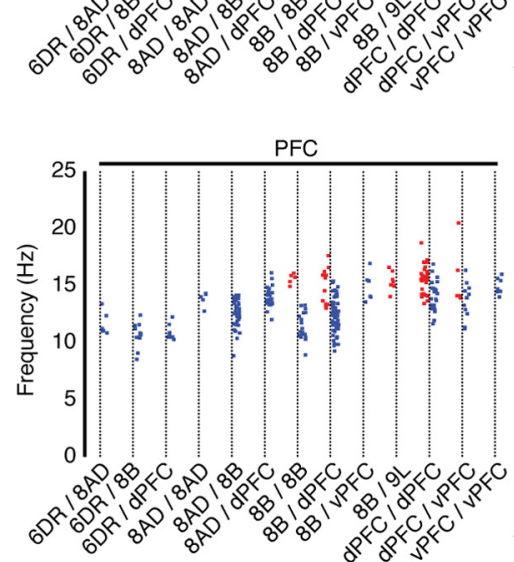

b
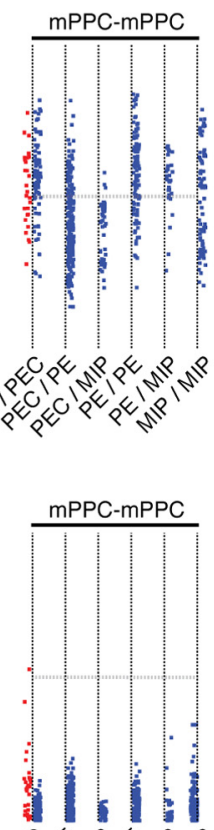

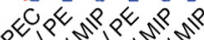

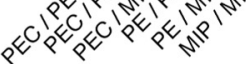

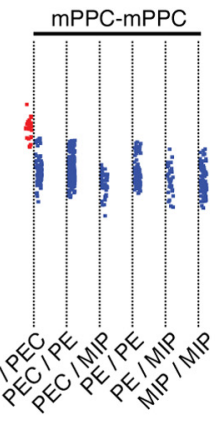

C

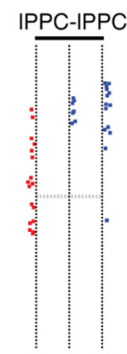

sens

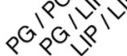

d

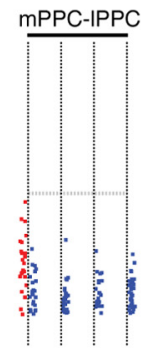

easeas e

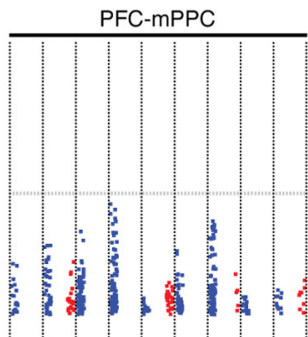

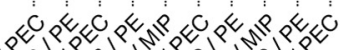
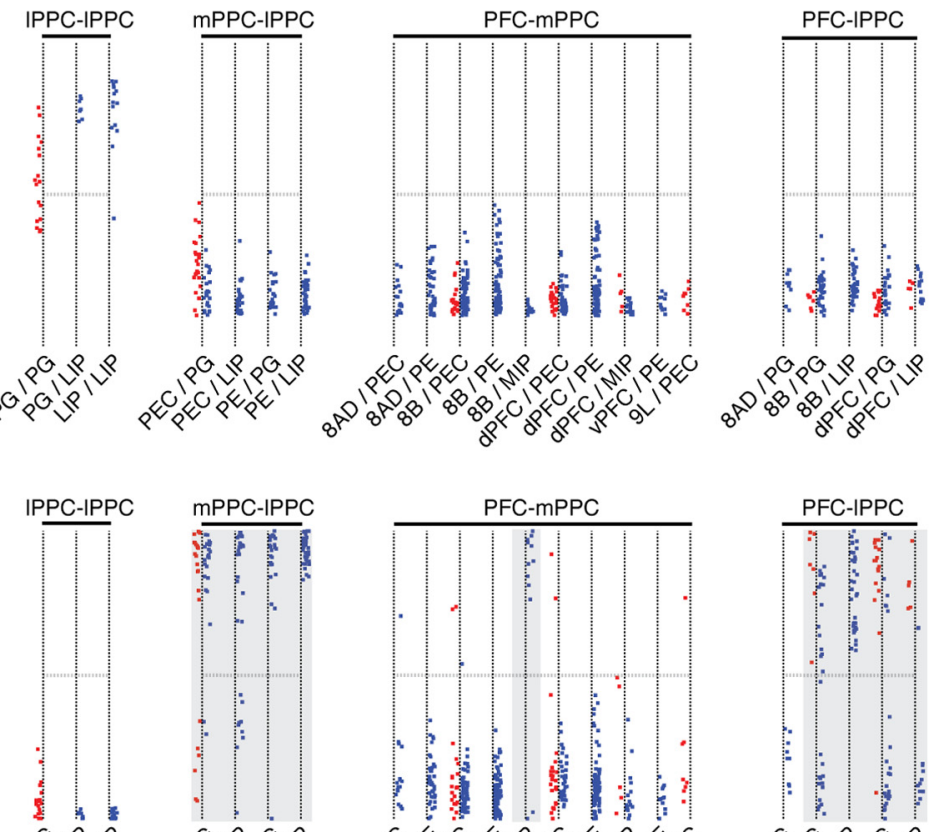

$b_{0} v_{s}$
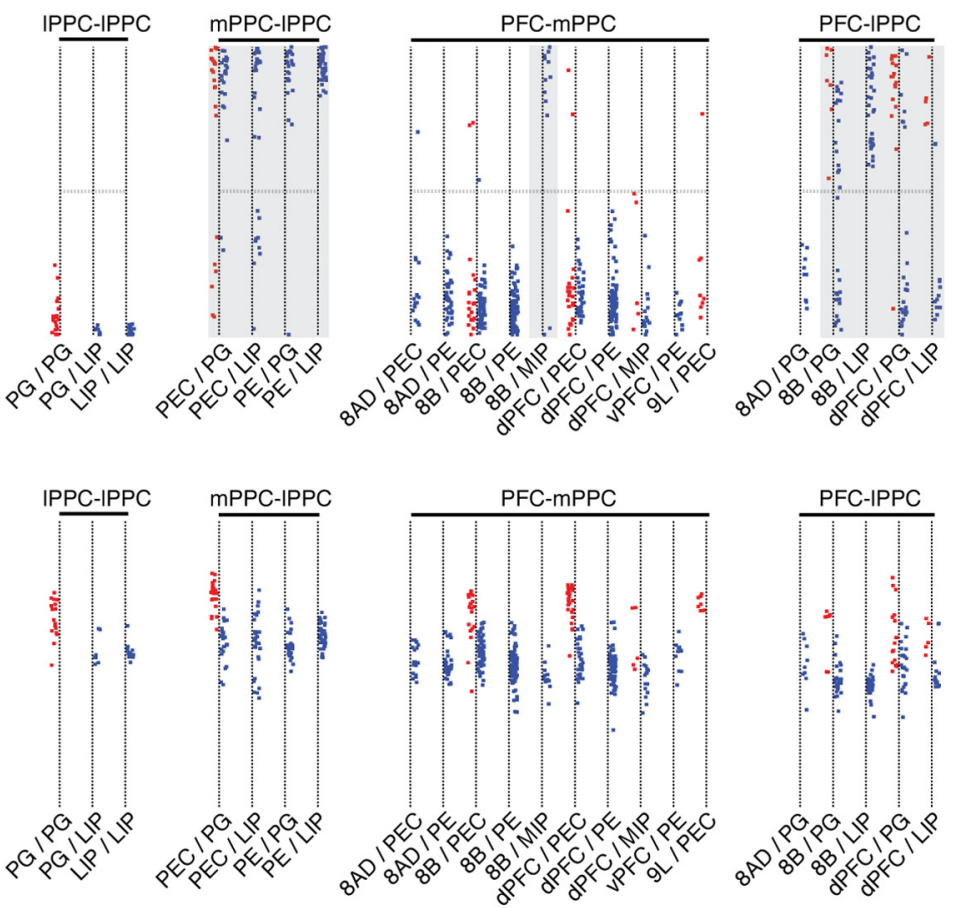

Figure 7. Distributions of the peak correlation coefficients (top row), absolute values of the relative phase angles (middle row), and the frequency at which the signals are correlated (bottom row) during the delay period (1.2-1.8 s) for signal pairs recorded in PFC ( $\boldsymbol{a}), \operatorname{mPPC}(\boldsymbol{b}), \operatorname{IPPC}(\boldsymbol{c}), \mathrm{mPPC}-\operatorname{IPPC}(\boldsymbol{d}), \operatorname{PFC}-\mathrm{mPPC}(\boldsymbol{e})$, and PFC-IPPC ( $\boldsymbol{f})$ for Monkey A (red) and Monkey B (blue). Only those areal combinations with five or more observations for at least one of the animals are included in the table. $\boldsymbol{d}-\boldsymbol{f}$, Light gray shading represents areal combinations with a high percentage of phase values between $90^{\circ}$ and $180^{\circ}$. Data points were jittered horizontally for better visualization.

significantly for PE-LIP (Fig. 10d). A related pattern of changes was apparent in the frontoparietal correlations. Significant increases occurred between $\mathrm{PPFC}$ and medial parietal areas PEC, PE, and MIP (Fig. 10e) and between prefrontal areas dPFC and 8B and lateral parietal areas PG and LIP (Fig. 10f). In addition, we found substantial task-dependent changes in relative phase (Fig. 10, bottom plots). Shifts in relative phase between the two task periods ranged from $0^{\circ}$ to $45^{\circ}$, with the largest shifts occurring most often between frontoparietal areal combinations (Fig. 10e,f).

To further explore the potential for these activity patterns to reorganize, we compared the delay period of the task (1.4-1.8 s) to the ITI shortly after the match period on error trials in Monkey B (For technical reasons, the ITI period was only recorded after incorrect trials in Monkey B; for further explanation, see Materials and Methods.) During the ITI of error trials, we observed a 


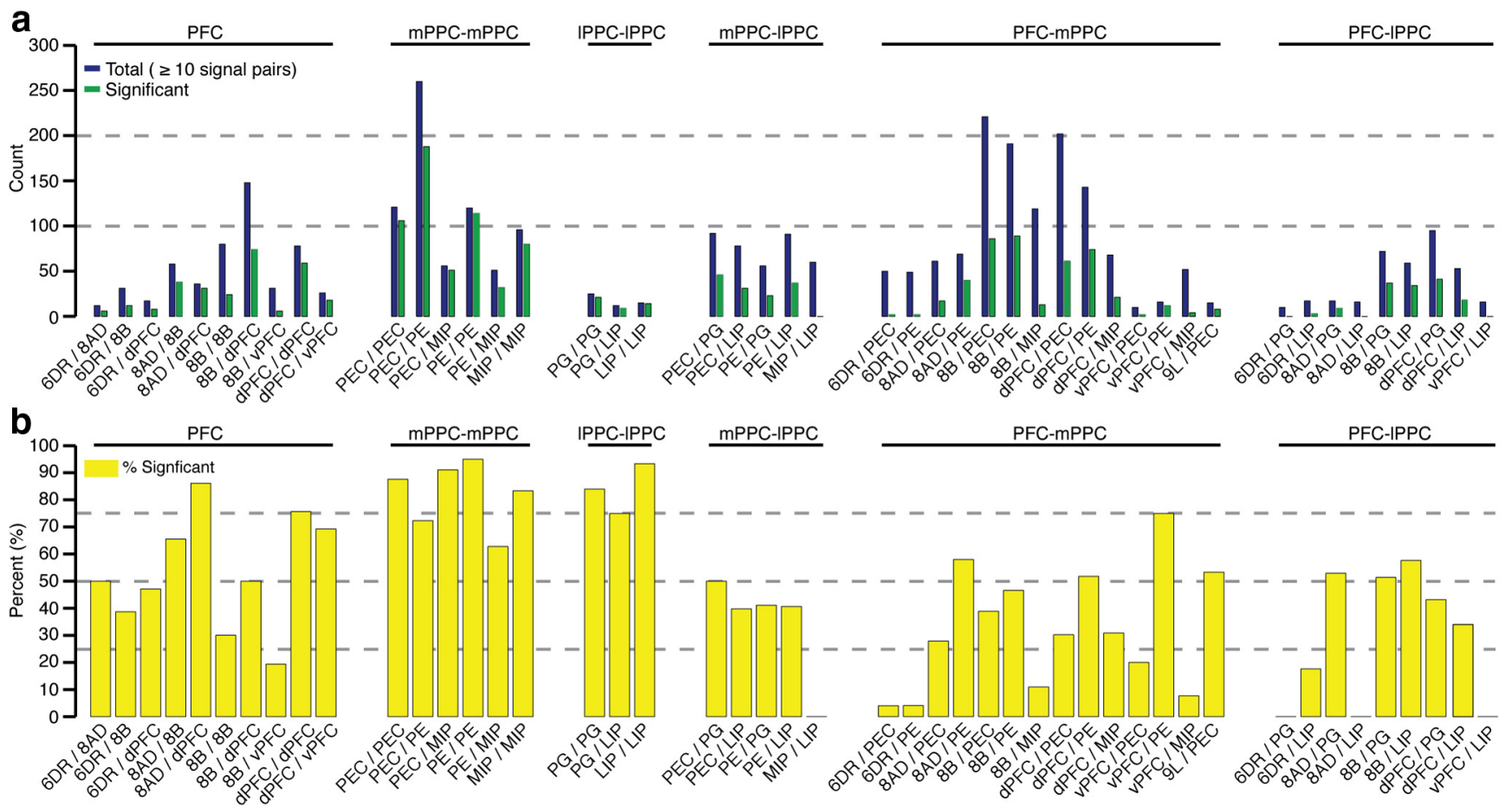

Figure 8. Summary of the counts and incidence of significance for all areal combinations with $\geq 10$ signal pairs. $\boldsymbol{a}$, Counts for the number of signal pairs (blue bars) and the number of significant signal pairs (green bars) during the delay period (1.2-1.8 s). $\boldsymbol{b}$, Percentage of significant signal pairs.

a

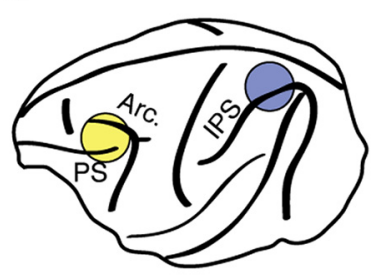

C

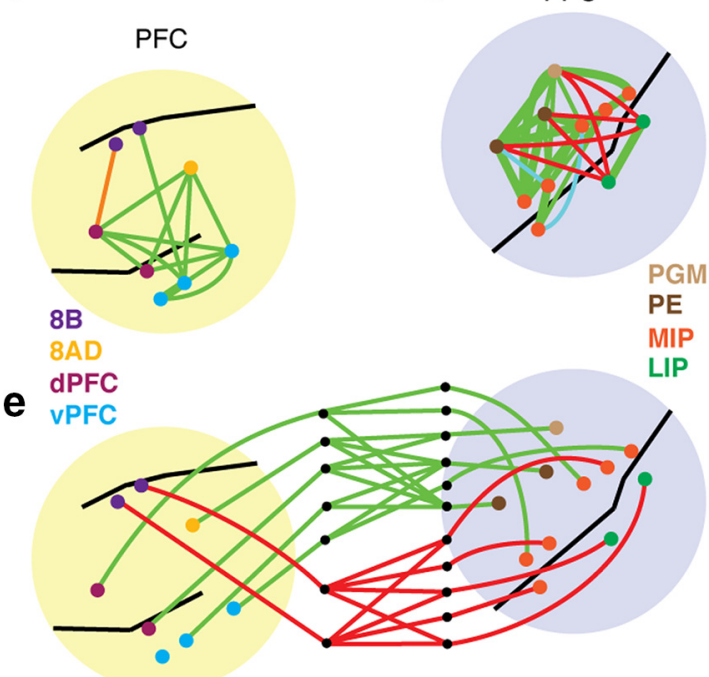

Figure 9. Example of a single recording session from Monkey B. $\boldsymbol{a}$, lllustration of the recording chamber locations. The names of the sulci are abbreviated as follows: PS, principle sulcus; Arc., arcuate sulcus; and IPS, intraparietal sulcus. $\boldsymbol{b}$, Color scale for the relative phase angles (absolute value). The magnitude of correlation is indicated by the line thickness. $\mathbf{c}-\boldsymbol{e}$, Intraareal and interareal phase angles and magnitudes illustrated on schematic drawings of the PFC (left) and PPC (right). Because of the chamber orientation and the curvature of the sulci, the recording locations do not always appear on the appropriate side of the sulcus. strong oscillatory response, visible in the LFP, which showed a marked change in relative phase among the signals (Fig. 11a). Analysis of the peak amplitude of these oscillatory bursts revealed that they occurred earlier in PPC $(671 \pm 96 \mathrm{~ms}$, after match onset) than PFC (769 $\pm 137 \mathrm{~ms}$, after match onset) (Wilcoxon rank sum test, $p \ll 0.001)$. Using this timing information, we centered the ITI analysis epoch over the peak amplitudes of the bursts (0.5-0.9 s after match onset; see Materials and Methods). Signal pairs were once again subjected to the fitting criteria for both task periods, resulting in a slightly different set of pairs (Table 2). Figure $11 b, c$ shows the time course of the trialaveraged cross-correlation for two of the signal pairs from Figure 11a. In these examples, the relative phase is near $180^{\circ}$ for the duration of the task and then abruptly flips to an in-phase relationship during the ITI. This effect, accompanied by an increase in correlation strength, occurs between PFC and PPC signals (Fig. $11 b$ ) and between the parietal signals on opposite sides of the IPS (Fig. 11c), demonstrating its widespread nature. Figure 11d shows the third frontoparietal pair, which shows a weak in-phase correlation before the sample, is largely uncorrelated during the delay, and then is highly correlated during the ITI, with no change in relative phase.

We quantified these task-dependent changes in the full dataset using the same method shown in Figure 10. Figure 12a-f (top plots) shows the difference distributions in correlation magnitude for each areal combination (outliers not shown). In general, correlation strength increased during the ITI, but the range of change was much larger than that seen during the task, indicating widespread activation and, with few exceptions, increased synchronization across the frontoparietal network. Correlation strength increased within and between several combinations of prefrontal areas $8 \mathrm{AD}, 8 \mathrm{~B}, \mathrm{dPFC}$, and $\mathrm{vPFC}$ (Fig. 12a), among parietal areas medial to the IPS (Fig. 12b), and somewhat heterogeneously among the other prefrontal and parietal areas (Fig. $12 c-f)$. We also found a striking change in relative phase relation- 
a

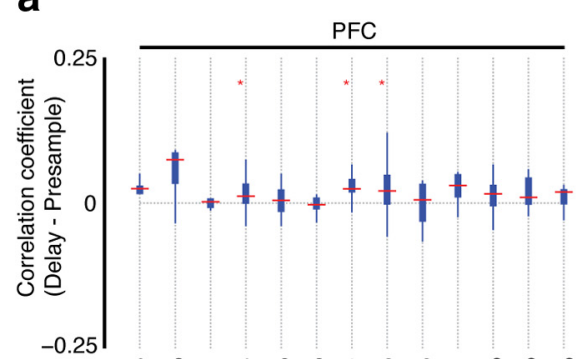

b

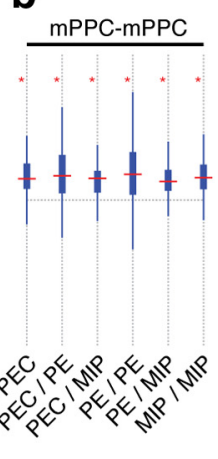

c d

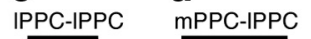

e

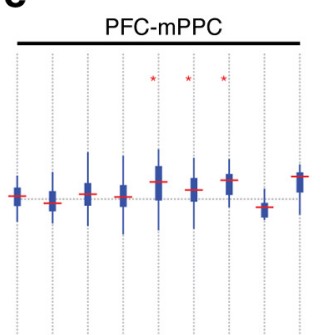

f PFC-IPPC
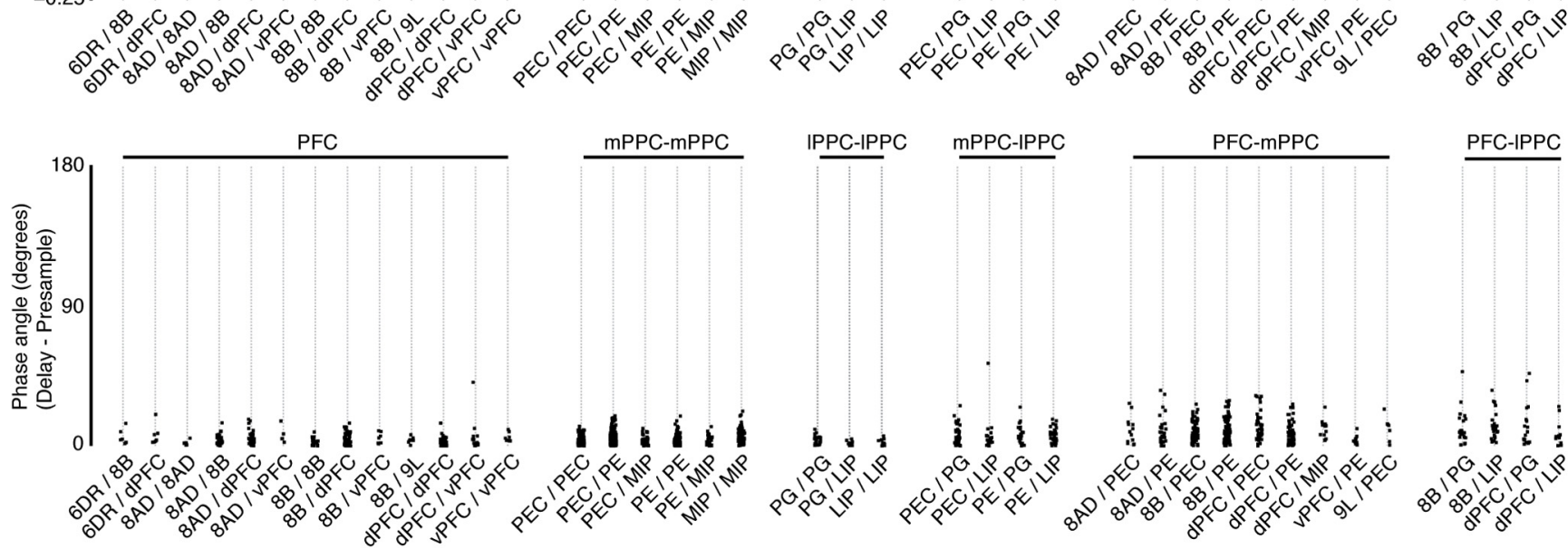

Figure 10. Distributions of the difference in correlation coefficients (top row) and relative phase angles (bottom row) between the delay period (1.4 $-1.8 \mathrm{~s}$ ) and the presample ( $0.1-0.5 \mathrm{~s}$ ) for signal pairs recorded in PFC $(\boldsymbol{a}), \operatorname{mPPC}(\boldsymbol{b})$, IPPC $(\boldsymbol{c}), \operatorname{mPPC}-\operatorname{IPPC}(\boldsymbol{d}), \operatorname{PFC}-\mathrm{mPPC}(\boldsymbol{e})$, and PFC-IPPC $(\boldsymbol{f})$. Data are combined across animals, and only those areal combinations with five or more observations are included in the table. Top row, Positive values indicate that the correlation is higher during the delay period. Red asterisks indicate that the hypothesis that the difference median is zero has been rejected (sign test, paired, two-sided, ${ }^{*} p<0.05$ using the Benjamini-Hochberg procedure to control the false discovery rate). Bottom row, Real values of the relative phase angles were used to calculate the difference between task periods, but for visualization purposes, the relative phase angle difference is presented as an absolute value. Also for visualization purposes, data points were jittered horizontally.

ships that occurred predominantly among signals separated by large distances (Fig. 12a-f, bottom plots). Whereas the changes in phase during the task were all $<50^{\circ}$ and often much closer to $0^{\circ}$ (Fig. 10), during the ITI following error trials we found numerous changes in phase exceeding $90^{\circ}$. Also, changes in correlation strength and relative phase were not obligatorily coupled. We found multiple areal combinations where correlation strength changed while relative phase remained stable, and vice versa.

A potential concern is that the patterns of correlation during the delay period may differ substantially between correct and incorrect trials, leading to the effects reported in Figures 11 and 12. We examined this possibility and found no significant difference in correlation magnitude across the population of areal combinations (paired sign test, $p=0.18$ ), and the mean difference in relative phase angle was $<4.5^{\circ}$.

\section{Discussion}

Our analysis reveals widespread, task-dependent temporal correlations of LFP signals in the $8-25 \mathrm{~Hz}$ frequency range within and between multiple areas of PFC and PPC during visual working memory. Correlation magnitude decreases with distance within and between adjacent cortical areas, whereas both the incidence and magnitude of correlation plateau to lower levels over larger distances. Also, some long-distance areal combinations show little or no evidence of correlation. Analysis of the relative phase angles revealed a clear bimodal distribution among signals recorded in widely separated cortical areas in both monkeys. Although this is not the first report of anti-phase correlations (Gregoriou et al., 2009), it is, to our knowledge, the first report of simultaneous in-phase and anti-phase correlations occurring in the same frequency range. Overall, our findings agree with what might be predicted from cortical anatomy (Markov et al., 2014). However, the bimodal distribution of relative phase, and the task dependence of correlation magnitude and phase, indicate that the interactions are not hard coded, but simply constrained by anatomy. Thus, our findings demonstrate that the correlation structure across the frontoparietal network can rapidly reorganize in a manner that is linked to behavior, indicating that largescale functional integration and segregation are dynamically regulated.

\section{Methodological considerations}

Because we used monopolar recording methods, volumeconducted signals may have contributed to our estimates of correlation. However, several factors suggest that volume conduction effects are minimal. First, intracortical microelectrodes are known to record highly local LFPs (Gray and Singer, 1989; Katzner et al., 2009; Wang and Roe, 2012; Xing et al., 2012) that exhibit minimal volume conduction (Engel et al., 1990). Thus, given that most of our recordings were separated by $>2 \mathrm{~mm}$, we expect volume conduction effects to be small. Second, if volume conduction were contributing significantly to our findings, we would not expect to find task- and time-dependent phase differences between sites (Salazar et al., 2012). Third, the presence of anti-phase correlations and the absence of correlations among some signals spanning the IPS indicate that even closely spaced electrodes, lying in separate cortical areas, record distinct neural signals. Together, this evidence argues against a significant contribution of volume conduction at all spatial scales measured. 
It could be argued that the phase differences we observe depend on the cortical depth of our recordings. Cortical LFP signals exhibit phase differences, and polarity reversals, as a function of depth (Mitzdorf and Singer, 1978; Murthy and Fetz, 1996; Bollimunta et al., 2008) that could lead to dispersion of our measured phase values. Several of our findings, however, indicate that sampling bias across a cortical dipole field cannot account for the anti-phase relationships we observe. For example, in order for laminar sampling bias to account for the antiphase correlations between areas PE and LIP (Fig. $7 d$ ), and the exclusively in-phase correlations within areas PE (Fig. $7 b$ ) and LIP (Fig. 7c), it would require that signal measurements were made on one side of the dipole (i.e., superficial layers) in one area and the opposite side of the dipole (i.e., deep layers) in the other area. Similar arguments apply to all the paired recordings made on the same side of the IPS (Fig. $7 b, c)$. Those phase distributions are somewhat dispersed, but there is no evidence of anti-phase relationships as might be expected from a dipole field. Furthermore, any doubt that the anti-phase relationships are functional, and not due to a sampling bias across a cortical dipole, is dispelled by the rapid and pronounced changes in relative phase following error trials (Figs. 11 and 12).

\section{Functional role of frontoparietal phase relationships}

How then should we interpret the bimodal distribution of intraparietal and frontoparietal phase relationships in Figures 6 and 7? The simplest interpretation is that during the task two large-scale frontoparietal networks are established: one involving in-phase coupling $\left(|\theta|<90^{\circ}\right)$ between medial parietal and prefrontal areas, and the other involving anti-phase coupling $\left(|\theta|>90^{\circ}\right)$ between lateral parietal and prefrontal areas. However, this interpretation may be too simplistic. For instance, signals in areas $8 \mathrm{~B}$ and MIP display largely anti-phase correlations, whereas signals in areas PG and LIP display differing combinations of in-phase and anti-phase correlations with prefrontal areas $8 \mathrm{AD}, 8 \mathrm{~B}$, and $\mathrm{dPFC}$. There are also a small percentage of intraprefrontal correlations with relative phase values near or $>90^{\circ}$. These data suggest that the phase of correlated activity reflects specific patterns of coupling among many of the prefrontal and parietal areas with a strong bias for anti-phase coupling across the intraparietal sulcus.

The question also arises as to how to interpret the specific relative phase values. Presumably in-phase and anti-phase coupling have differing functional consequences. However, given the large distances separating the recorded sites, with transmission delays ranging from $\sim 5$ to $10 \mathrm{~ms}$, there is no simple functional interpretation. One possibility is that the anti-phase correlations occurring across the IPS, and between certain frontoparietal areal
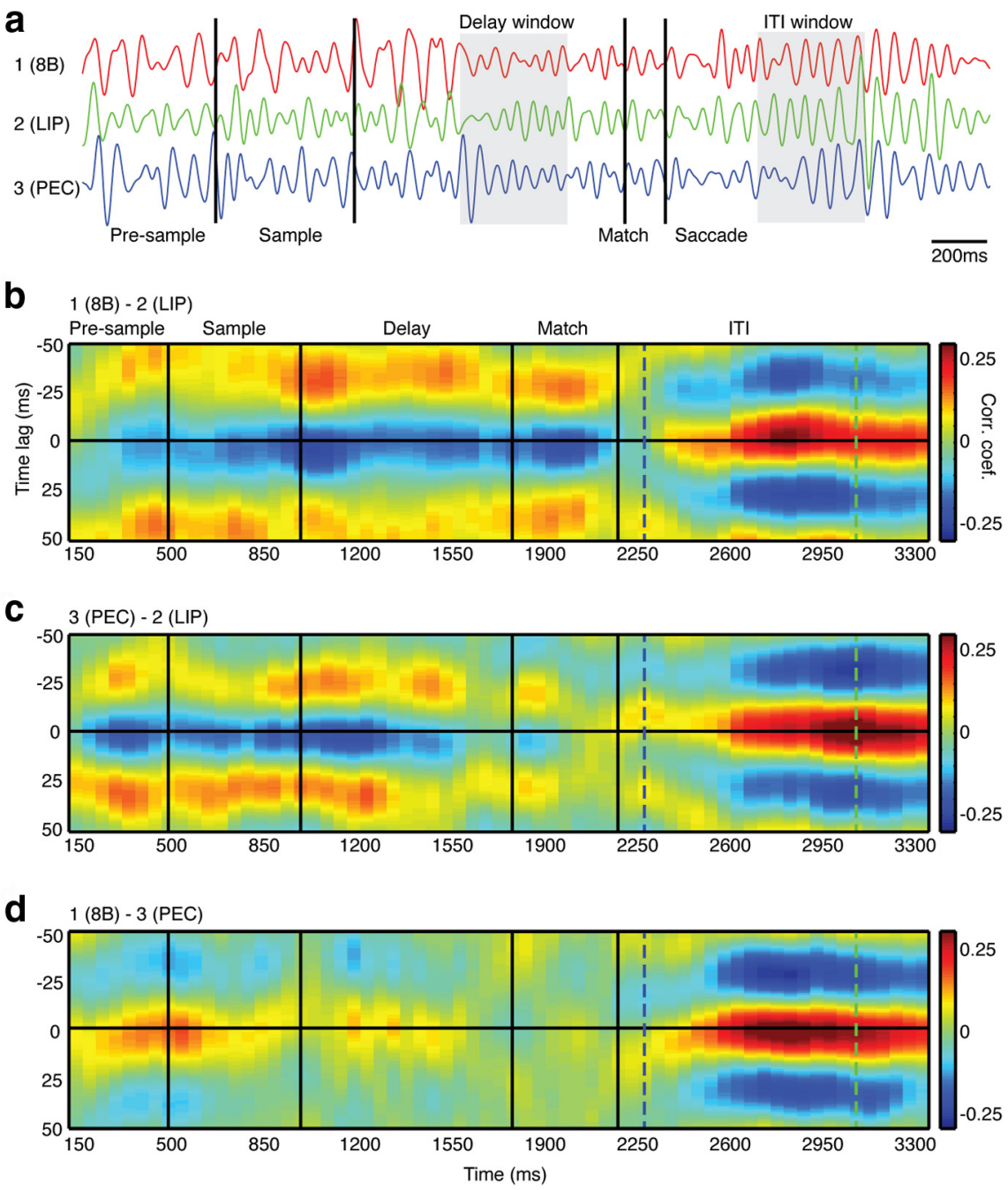

Figure 11. Example of the ITI phase flips during a single trial and averaged over all incorrect trials for a single recording session from Monkey B. $a$, One PFC (red) and two PPC channels (green and blue) recorded simultaneously. Data are bandpass filtered from 8 to $25 \mathrm{~Hz}$. Gray shading represents the time window used during the delay and ITI periods. $\boldsymbol{b}$ - $\boldsymbol{d}$, Average correlograms as a black lines indicate the sample onset, sample offset, and earliest match onset, respectively. The dashed vertical blue and green lines indicate the earliest start time and latest end time for the ITI analysis window, respectively.

combinations, as well as the low incidence of correlation between certain areal combinations, such as MIP and LIP, reflect functional segregation that is imposed by the oculomotor and visual mnemonic nature of the task. This seems likely, given the differing functional properties of neurons in these various prefrontal (Petrides, 2005; Lanzilotto et al., 2013) and posterior parietal (Breveglieri et al., 2008; Andersen and Cui 2009) cortical areas.

Other aspects of the frontoparietal phase relationships require explanation. The data in Figure 4 suggest that in-phase and antiphase coupling between PFC and medial and lateral parietal areas occur simultaneously, whereas the results in Figure 9 suggest some degree of independence in the frontoparietal networks. However, the interpretation of these findings must be gauged by the fact that the median value of the long-distance correlation coefficients is $<0.2$. This indicates that most of the time the signals in widely separated areas of the frontoparietal network are independent and that coupling between distant areas is likely to be highly transient (Gray et al., 1992). Thus, analysis of the temporal properties of the correlations on single trials will be necessary to reveal the underlying spatiotemporal organization. 
a
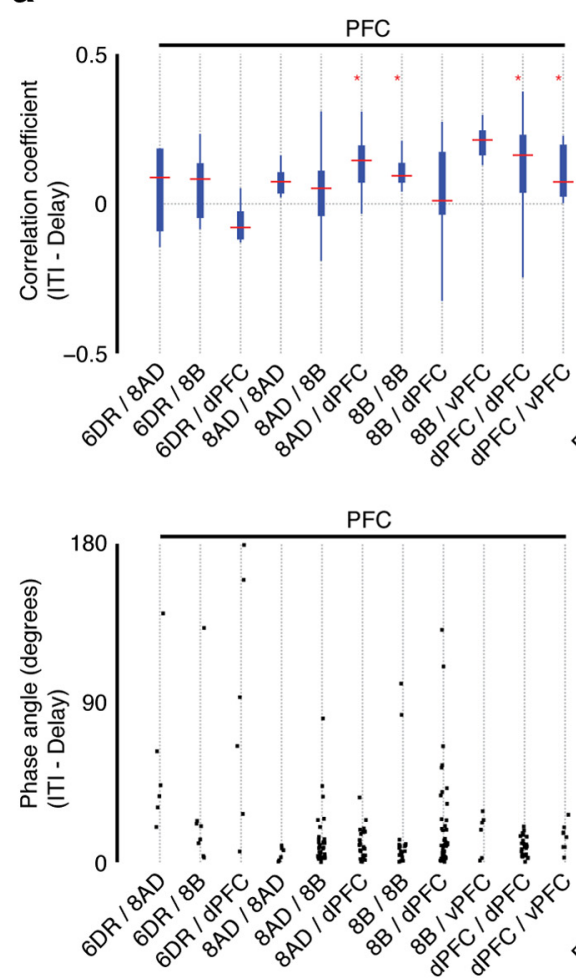

b

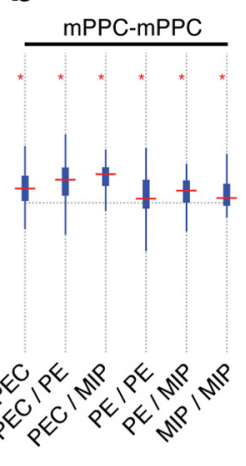

$\sigma_{0} \leqslant s$ IPPC-IPPC $\underline{\text { mPPC-IPPC }}$

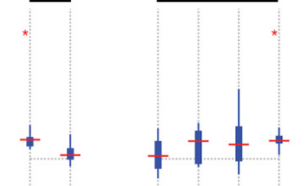

e

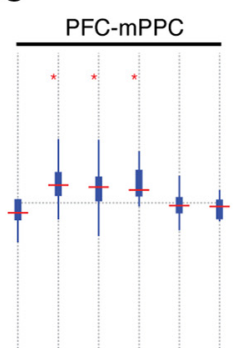

f

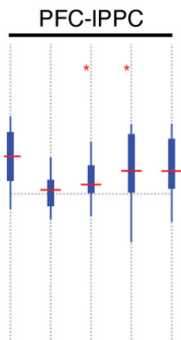

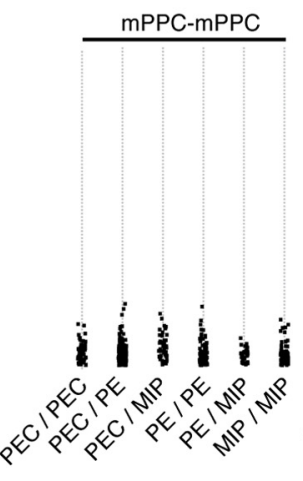
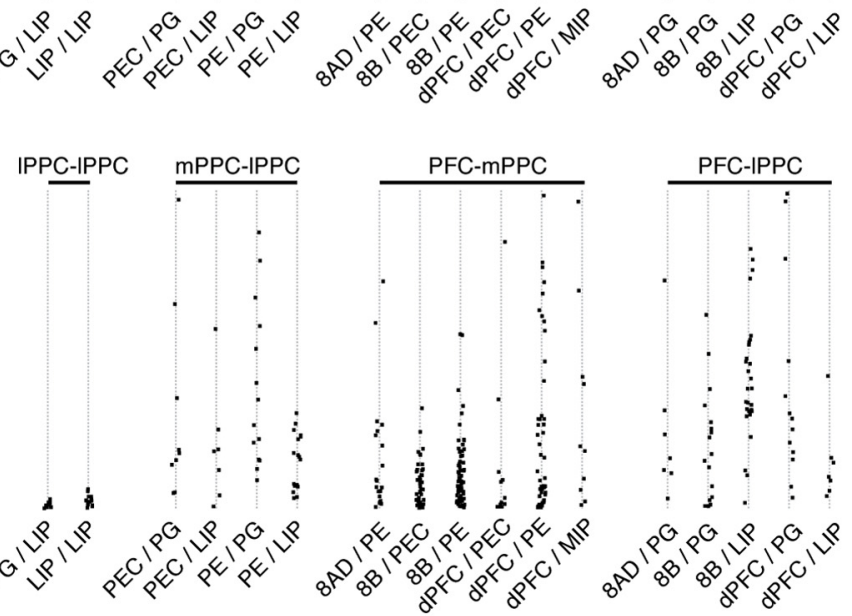

Figure 12. Distributions of the difference in correlation coefficients (top row) and relative phase angles (bottom row) between the ITI period ( $0.5-0.9 \mathrm{~s}$ locked to match onset) and the delay period (1.4-1.8s) for signal pairs recorded in $\operatorname{PFC}(\boldsymbol{a}), \mathrm{mPPC}(\boldsymbol{b}), \operatorname{IPPC}(\boldsymbol{c}), \mathrm{mPPC}-\operatorname{IPPC}(\boldsymbol{d}), \operatorname{PFC}-\mathrm{mPPC}(\boldsymbol{e})$, and PFC-IPPC $(\boldsymbol{f})$, during incorrect trials. Data are only from Monkey B, and only those areal combinations with five or more observations are included in the table. Top row, Positive values indicate that the correlation is higher during the ITI period. Red asterisks indicate that the hypothesis that the difference median is zero has been rejected (sign test, paired, two-sided, ${ }^{*} p<0.05$ using the Benjamini-Hochberg procedure to control the false discovery rate). Bottom row, Real values of the relative phase angles were used to calculate the difference between task periods, but for visualization purposes, the relative phase angle difference is presented as an absolute value. Also for visualization purposes, data points were jittered horizontally.

Our previous findings that frontoparietal coherence in the $12-22 \mathrm{~Hz}$ frequency range is content specific (Salazar et al., 2012) imply that the corresponding phase relationships may also contribute to short-term representations. Determining if and how this occurs will require a more extensive analysis than we have conducted here. The relative phase and frequency of coherent activity may vary systematically with different aspects of working memory, such as content, load, and task dependence, thereby adding further dimensions to the representations. Another possibility, discussed above, may be that the bimodal distribution of relative phases provides a mechanism for task-dependent segregation of activity into distinct networks, thereby reducing potential interference among competing representations. This could be tested by switching from a saccade-based task to one in which choices are based on varying combinations of reach and saccade. In such an experiment, the phase relationships between different components of the frontoparietal network may change as the task switches from choices based on saccades to reach to a combination of the two (Dean et al., 2012).

Our finding of abrupt and marked changes in frontoparietal correlations following error trials (Figs. 11 and 12) suggests a link to the cognitive processing of errors (Larson et al., 2014). The widely distributed and highly synchronized bursts of activity may correspond to the well-documented error-related negativity (Falkenstein et al., 1991; Gehring et al., 1993) and reflect processes related to reinforcement learning (Holroyd and Coles, 2002) mediated by midbrain dopamine systems (Schultz et al., 1997). However, the present data are limited, and further experiments are required to test these hypotheses.

\section{Coordination in large-scale networks}

The phase of rhythmic correlation has been postulated to be a critical variable controlling the selective transmission, or communication, of signals between separate neuronal populations (Fries, 2005; Womelsdorf et al., 2007). Communication between neuronal groups is thought to be most effective when they oscillate at the same frequency and are synchronized at relative phases near $0^{\circ}$. This model is consistent with our understanding of synaptic integration (Abeles, 1982; König et al., 1995; Azouz and Gray, 2000, 2003) and is supported by experimental evidence (Engel et al., 1991a, b; Roelfsema et al., 1997; Salazar et al., 2004). Other studies have found substantial phase differences between distant neuronal populations (Gregoriou et al., 2009; Liebe et al., 2012) and suggested that these effects reflect directional influences mediated through relatively fixed conduction delays. However, neither of these perspectives is fully consistent with our findings. We find robust correlations in a common frequency range over a wide span of spatial separations that exhibit a bimodal distribution of relative phases. Moreover, the phase relations are not fixed. They vary during the task and exhibit large transitions during the intertrial interval following error trials. A potentially more favorable interpretation of these findings is that these dynamics are a product of global cooperation across the brain and that changes in correlation magnitude and phase reflect shifts in global coordination states that are not predictable on the basis of expected transmission delays (Bressler and Kelso, 2001; Tognoli and Kelso, 2014). 


\section{References}

Abeles M (1982) Role of the cortical neuron: integrator or coincidence detector? Isr J Med Sci 18:83-92. Medline

Andersen RA, Cui H (2009) Intention, action planning, and decision making in parietal-frontal circuits. Neuron 63:568-583. CrossRef Medline

Asaad WF, Eskandar EN (2008) A flexible software tool for temporallyprecise behavioral control in Matlab. J Neurosci Methods 174:245-258. CrossRef Medline

Azouz R, Gray CM (2000) Dynamic spike threshold reveals a mechanism for synaptic coincidence detection in cortical neurons in vivo. Proc Natl Acad Sci U S A 97:8110-8115. CrossRef Medline

Azouz R, Gray CM (2003) Adaptive coincidence detection and dynamic gain control in visual cortical neurons in vivo. Neuron 37:513-523. CrossRef Medline

Bollimunta A, Chen Y, Schroeder CE, Ding M (2008) Neuronal mechanisms of cortical alpha oscillations in awake-behaving macaques. J Neurosci 28:9976-9988. CrossRef Medline

Bressler SL (1995) Large-scale cortical networks and cognition. Brain Res Rev 20:288-304. CrossRef Medline

Bressler SL, Kelso JA (2001) Cortical coordination dynamics and cognition. Trends Cogn Sci 5:26-36. CrossRef Medline

Bressler SL, Menon V (2010) Large-scale brain networks in cognition: emerging methods and principles. Trends Cogn Sci 14:277-290. CrossRef Medline

Bressler SL, Coppola R, Nakamura R (1993) Episodic multiregional cortical coherence at multiple frequencies during visual task performance. Nature 366:153-156. CrossRef Medline

Breveglieri R, Galletti C, Monaco S, Fattori P (2008) Visual, somatosensory, and bimodal activities in the macaque parietal area PEc. Cereb Cortex 18:806-816. CrossRef Medline

Brodmann K (1909) Vergleichende Lokalisationslehre der Grosshirnrinde: in ihren Prinzipien dargestellt auf Grund des Zellenbaues. Barth, Leipzig.

Buschman TJ, Miller EK (2007) Top-down versus bottom-up control of attention in the prefrontal and posterior parietal cortices. Science 315: 1860-1862. CrossRef Medline

Buzsáki G (2006) Rhythms of the brain. New York: Oxford UP.

Buzsáki G, Draguhn A (2004) Neuronal oscillations in cortical networks. Science 304:1926-1929. CrossRef Medline

Crowe DA, Goodwin SJ, Blackman RK, Sakellaridi S, Sponheim SR, MacDonald AW 3rd, Chafee MV (2013) Prefrontal neurons transmit signals to parietal neurons that reflect executive control of cognition. Nat Neurosci 16:1484-1491. CrossRef Medline

Dean HL, Hagan MA, Pesaran B (2012) Only coherent spiking in posterior parietal cortex coordinates looking and reaching. Neuron 73:829-841. CrossRef Medline

Desimone R (1998) Visual attention mediated by biased competition in extrastriate visual cortex. Philos Trans R Soc Lond B Biol Sci 353:1245-1255. CrossRef Medline

Destexhe A, Contreras D, Steriade M (1999) Spatiotemporal analysis of local field potentials and unit discharges in cat cerebral cortex during natural wake and sleep states. J Neurosci 19:4595-4608. Medline

DeYoe EA, Van Essen DC (1988) Concurrent processing streams in monkey visual cortex. Trends Neurosci 11:219-226. CrossRef Medline

Engel AK, König P, Gray CM, Singer W (1990) Stimulus-dependent neuronal oscillations in cat visual cortex: inter-columnar interaction as determined by cross-correlation analysis. Eur J Neurosci 2:588-606. CrossRef Medline

Engel AK, König P, Kreiter AK, Singer W (1991a) Interhemispheric synchronization of oscillatory neuronal responses in cat visual cortex. Science 252:1177-1179. CrossRef Medline

Engel AK, Kreiter AK, König P, Singer W (1991b) Synchronization of oscillatory neuronal responses between striate and extrastriate visual cortical areas of the cat. Proc Natl Acad Sci U S A 88:6048-6052. CrossRef Medline

Falkenstein M, Hohnsbein J, Hoormann J, Blanke L (1991) Effects of crossmodal divided attention on late ERP components: II. Error processing in choice reaction tasks. Electroencephalogr Clin Neurophysiol 78:447-455. CrossRef Medline

Fell J, Axmacher N (2011) The role of phase synchronization in memory processes. Nat Rev Neurosci 12:105-118. CrossRef Medline

Felleman DJ, Van Essen DC (1991) Distributed hierarchical processing in the primate cerebral cortex. Cereb Cortex 1:1-47. CrossRef Medline

Freeman WJ (1975) Mass action in the nervous system. New York: Academic.

Fries P (2005) A mechanism for cognitive dynamics: neuronal communication through neuronal coherence. Trends Cogn Sci 9:474-480. CrossRef Medline
Gehring WJ, Goss B, Coles MGH, Meyer DE, Donchin E (1993) A neural system for error detection and compensation. Psychol Sci 4:385-390. CrossRef

Goldman-Rakic PS (1988) Topography of cognition: parallel distributed networks in primate association cortex. Annu Rev Neurosci 11:137-156. CrossRef Medline

Gray CM (1994) Synchronous oscillations in neuronal systems: mechanisms and functions. J Comput Neurosci 1:11-38. CrossRef Medline

Gray CM, Singer W (1989) Stimulus-specific neuronal oscillations in orientation columns of cat visual cortex. Proc Natl Acad Sci U S A 86:16981702. CrossRef Medline

Gray CM, Skinner JE (1988) Field potential response changes in the rabbit olfactory bulb accompany behavioral habituation during the repeated presentation of unreinforced odors. Exp Brain Res 73:189-197. CrossRef Medline

Gray CM, Engel AK, König P, Singer W (1992) Synchronization of oscillatory neuronal responses in cat striate cortex: temporal properties. Vis Neurosci 8:337-347. CrossRef Medline

Gray CM, Goodell B, Lear A (2007) Multichannel micromanipulator and chamber system for recording multineuronal activity in alert, nonhuman primates. J Neurophysiol 98:527-536. CrossRef Medline

Gregoriou GG, Gotts SJ, Zhou H, Desimone R (2009) High-frequency, long-range coupling between prefrontal and visual cortex during attention. Science 324:1207-1210. CrossRef Medline

Holroyd CB, Coles MG (2002) The neural basis of human error processing: reinforcement learning, dopamine, and the error-related negativity. Psychol Rev 109:679-709. CrossRef Medline

Judge SJ, Richmond BJ, Chu FC (1980) Implantation of magnetic search coils for measurement of eye position: an improved method. Vision Res 20:535-538. CrossRef Medline

Katzner S, Nauhaus I, Benucci A, Bonin V, Ringach DL, Carandini M (2009) Local origin of field potentials in visual cortex. Neuron 61:35-41. CrossRef Medline

Kelso JA (1995) Dynamic patterns: the self organization of brain and behaviour. Cambridge, MA: Massachusetts Institute of Technology.

König P (1994) A method for the quantification of synchrony and oscillatory properties of neuronal activity. J Neurosci Methods 54:31-37. CrossRef Medline

König P, Engel AK, Roelfsema PR, Singer W (1995) How precise is neuronal synchronization? Neural Comput 7:469-485. CrossRef Medline

Lanzilotto M, Perciavalle V, Lucchetti C (2013) A new field in monkey's frontal cortex: premotor ear-eye field (PEEF). Neurosci Biobehav Rev 37:1434-1444. CrossRef Medline

Larson MJ, Clayson PE, Clawson A (2014) Making sense of all the conflict: a theoretical review and critique of conflict-related ERPs. Int J Psychophysiol 93:283-297. CrossRef Medline

Liebe S, Hoerzer GM, Logothetis NK, Rainer G (2012) Theta coupling between $\mathrm{V} 4$ and prefrontal cortex predicts visual short-term memory performance. Nat Neurosci 15:456-462, S1-S2. CrossRef Medline

Markov NT, Ercsey-Ravasz MM, Ribeiro Gomes AR, Lamy C, Magrou L, Vezoli J, Misery P, Falchier A, Quilodran R, Gariel MA, Sallet J, Gamanut R, Huissoud C, Clavagnier S, Giroud P, Sappey-Marinier D, Barone P, Dehay C, Toroczkai Z, Knoblauch K, et al. (2014) A weighted and directed interareal connectivity matrix for macaque cerebral cortex. Cereb Cortex 24:17-36. Medline

Mesulam MM (1990) Large-scale neurocognitive networks and distributed processing for attention, language, and memory. Ann Neurol 28:597613. CrossRef Medline

Miller EK (2013) The "working" of working memory. Dialogues Clin Neurosci 15:411-418. Medline

Mitzdorf U, Singer W (1978) Prominent excitatory pathways in the cat visual cortex (A 17 and A 18): a current source density analysis of electrically evoked potentials. Exp Brain Res 33:371-394. Medline

Murthy VN, Fetz EE (1996) Oscillatory activity in sensorimotor cortex of awake monkeys: synchronization of local field potentials and relation to behavior. J Neurophysiol 76:3949-3967. Medline

Paxinos G, Huang XF, Toga AW (1999) The rhesus monkey brain in stereotaxic coordinates. San Diego: Academic.

Petrides M (2005) Lateral prefrontal cortex: architectonic and functional organization. Philos Trans R Soc Lond B Biol Sci 360:781-795. CrossRef Medline

Popa D, Popescu AT, Paré D (2009) Contrasting activity profile of two distributed cortical networks as a function of attentional demands. J Neurosci 29:1191-1201. CrossRef Medline 
Roelfsema PR, Engel AK, König P, Singer W (1997) Visuomotor integration is associated with zero time-lag synchronization among cortical areas. Nature 385:157-161. CrossRef Medline

Salazar RF, Kayser C, König P (2004) Effects of training on neuronal activity and interactions in primary and higher visual cortices in the alert cat. J Neurosci 24:1627-1636. CrossRef Medline

Salazar RF, Dotson NM, Bressler SL, Gray CM (2012) Content-specific fronto-parietal synchronization during visual working memory. Science 338:1097-1100. CrossRef Medline

Saleem KS, Logothetis NK (2007) Atlas of the rhesus monkey brain. London: Academic.

Schultz W, Dayan P, Montague PR (1997) A neural substrate of prediction and reward. Science 275:1593-1599. CrossRef Medline

Siegel M, Donner TH, Engel AK (2012) Spectral fingerprints of largescale neuronal interactions. Nat Rev Neurosci 13:121-134. CrossRef Medline

Singer W, Gray CM (1995) Visual feature integration and the temporal correlation hypothesis. Annu Rev Neurosci 18:555-586. CrossRef Medline

Tognoli E, Kelso JA (2014) The metastable brain. Neuron 81:35-48. CrossRef Medline
Tononi G, Edelman GM, Sporns O (1998) Complexity and coherency: integrating information in the brain. Trends Cogn Sci 2:474-484. CrossRef Medline

Van Essen DC, Glasser MF, Dierker DL, Harwell J (2012) Cortical parcellations of the macaque monkey analyzed on surface-based atlases. Cereb Cortex 22:2227-2240. CrossRef Medline

Varela F, Lachaux JP, Rodriguez E, Martinerie J (2001) The brainweb: phase synchronization and large-scale integration. Nat Rev Neurosci 2:229239. CrossRef Medline

Wang Z, Roe AW (2012) Columnar specificity of microvascular oxygenation and blood flow response in primary visual cortex: evaluation by local field potential and spiking activity. J Cereb Blood Flow Metab 32:616. CrossRef Medline

Womelsdorf T, Schoffelen JM, Oostenveld R, Singer W, Desimone R, Engel AK, Fries P (2007) Modulation of neuronal interactions through neuronal synchronization. Science 316:1609-1612. CrossRef Medline

Xing D, Yeh CI, Burns S, Shapley RM (2012) Laminar analysis of visually evoked activity in the primary visual cortex. Proc Natl Acad Sci U S A 109:13871-13876. CrossRef Medline

Zeki S, Shipp S (1988) The functional logic of cortical connections. Nature 335:311-317. CrossRef Medline 